\title{
Preschool children's coping responses and outcomes in the vaccination context: Child and caregiver transactional and longitu....
}

Article in Pain - October 2017

DOI: $10.1097 /$ j.pain. 0000000000001092

CITATION

1

5 authors, including:

Rebecca R Pillai Riddell

York University

107 PUBLICATIONS 1,317 CITATIONS

SEE PROFILE

\section{Hartley Garfield}

University of Toronto

23 PUBLICATIONS 200 CITATIONS

SEE PROFILE
READS

11

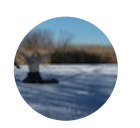

Robert A Cribbie

York University

73 PUBLICATIONS 2,145 CITATIONS

SEE PROFILE

Saul Greenberg

SickKids

29 PUBLICATIONS 467 CITATIONS

SEE PROFILE

Some of the authors of this publication are also working on these related projects: 


\title{
Preschool children's coping responses and outcomes in the vaccination context: child and caregiver transactional and longitudinal relationships
}

\author{
Lauren Campbell $^{\mathrm{a}}$, Rebecca Pillai Riddell ${ }^{\mathrm{a}, \mathrm{b}, \mathrm{c}, \star}$, Robert Cribbie ${ }^{\mathrm{a}}$, Hartley Garfield ${ }^{\mathrm{b}, \mathrm{c}}$, Saul Greenberg ${ }^{\mathrm{b}, \mathrm{c}}$
}

\begin{abstract}
This article, based on 2 companion studies, presents an in-depth analysis of preschoolers coping with vaccination pain. Study 1 used an autoregressive cross-lagged path model to investigate the dynamic and reciprocal relationships between young children's coping responses (how they cope with pain and distress) and coping outcomes (pain behaviors) at the preschool vaccination. Expanding on this analysis, study 2 then modeled preschool coping responses and outcomes using both caregiver and child variables from the child's 12-month vaccination $(n=548)$, preschool vaccination $(n=302)$, and a preschool psychological assessment $(n=172)$. Summarizing over the 5 path models and post hoc analyses over the 2 studies, novel transactional and longitudinal pathways predicting preschooler coping responses and outcomes were elucidated. Our research has provided empirical support for the need to differentiate between coping responses and coping outcomes: 2 different, yet interrelated, components of "coping." Among our key findings, the results suggest that a preschooler's ability to cope is a powerful tool to reduce pain-related distress but must be maintained throughout the appointment; caregiver behavior and poorer pain regulation from the 12-month vaccination appointment predicted forward to preschool coping responses and/or outcomes; robust concurrent relationships exist between caregiver behaviors and both child coping responses and outcomes, and finally, caregiver behaviors during vaccinations are not only critical to both child pain coping responses and outcomes in the short- and long-term but also show relationships to broader child cognitive abilities as well.
\end{abstract}

Keywords: Infant, Child, Caregiver, Coping, Pain, Vaccination

\section{Introduction}

"Coping" is a complex construct. ${ }^{11}$ It has been used as a catch-all term referring to behaviours that reduce distress (eg, Refs. $11,12,18,23)$ as well as to the actual reduction of distress. ${ }^{41,47}$ Almost 25 years ago, Rudolph et al..$^{40}$ argued that for the field of pediatric pain and coping to move forward, a clear differentiation must be made between "coping responses" and "coping outcomes." The former was defined as intentional physical or mental actions (eg, deep breathing, distraction) in response to a perceived stressor and the latter was defined as the consequences of one's coping responses (eg, crying or screaming). To increase clarity in the field of pediatric pain and coping, it is critical to disentangle coping responses from coping outcomes (and to use these terms specifically).

\footnotetext{
Sponsorships or competing interests that may be relevant to content are disclosed at the end of this article.

${ }^{a}$ York University, Toronto, ON, Canada, ${ }^{b}$ Hospital for Sick Children, Toronto, ON, Canada, ${ }^{C}$ University of Toronto, Toronto, ON, Canada

${ }^{*}$ Corresponding author. Address: Department of Psychology, Faculty of Health, The Opportunities to Understand Childhood Hurt (OUCH) Laboratory, York University, Room 038J Atkinson College Building, 4700 Keele St, Toronto, ON M3J 1P3,

Canada. Tel.: +416-736-2100 x20177; fax: +416-736-5814. E-mail address: rpr@ yorku.ca (R. Pillai Riddell).
}

Supplemental digital content is available for this article. Direct URL citations appear in the printed text and are provided in the HTML and PDF versions of this article on the journal's Web site (www. painjournalonline.com).

PAIN 159 (2018) 314-330

(C) 2017 International Association for the Study of Pain

http://dx.doi.org/10.1097/j.pain.00000000000001092
A systematic review recently sorted and synthesized coping responses and coping outcomes in children aged 3 to 12 years. ${ }^{16}$ This review highlighted the paucity of studies, taking account of the phase of the needle-related procedure, the lack of developmental (age-related) considerations, the lack of longitudinal design, and the importance of caregiver variables and the child's developing cognitive abilities.

We present 2 studies:

In study 1 , we examine the reciprocal relationships between children's coping responses and coping outcomes during the preschool vaccination. We hypothesized that

(1) Preschooler coping responses would predict subsequent coping outcomes.

(2) Coping responses would predict subsequent coping outcomes.

(3) Concurrent coping responses and coping outcomes would be negatively related.

(4) Preceding coping responses would negatively predict subsequent coping outcomes.

(5) Preceding coping outcomes would negatively predict subsequent coping responses.

In study 2, we examine the prediction of preschool children's coping responses and coping outcomes (during the first 2 minutes post-vaccination) using a broad array of caregiver and child variables from both the 12-month and preschool stage. Four broad hypotheses shaped the predictive pathways across the 4 models. We hypothesized that

(1) Caregiver behavioral variables from the 12-month vaccination (caregiver sensitivity, proximal soothing, verbal reassurance) 
would predict parallel caregiver behavioral variables at their child's preschool vaccination (caregiver sensitivity, copingpromoting behaviors, distress-promoting behaviors), which in turn would predict the preschooler's vaccination behavior (coping responses and outcomes).

(2) Greater caregiver sensitivity and proximal soothing during the 12-month vaccination would predict more optimal preschooler cognitive skills, which would then predict more optimal preschooler coping responses and outcomes. Specifically, sensitive caregiving and physical touch have been associated with stronger cognitive skills in young children, 6,9,14,29,33,34 and cognitive skills may subsume the construct of children's coping. ${ }^{42}$ In terms of caregiver behaviors in the vaccination predicting children's cognitive skills, caregiver behavior during vaccination is believed to be representative of broader patterns of caregiver behavior.

(3) Greater infant pain-related distress would predict less optimal caregiver cognition (worry) at the preschool vaccination which in turn would predict less optimal caregiver behavior (more distress-promoting behaviors, less caregiver copingpromoting behaviors, and lower caregiver sensitivity), which in turn would predict less optimal preschooler's coping responses and outcomes.

(4) Greater infant pain-related distress would predict less optimal preschooler coping responses and outcomes.

Of note for the current study, while "coping outcomes" are a multidimensional construct, ${ }^{34}$ the present paper focused on the behavioural dimension of "coping outcomes," which were operationalized as behavioral pain-related distress.

\section{Methods}

\subsection{Study population}

The data from the present study are a part of an ongoing Canadian longitudinal study (The $\mathrm{OUCH}$ cohort) that followed caregivers and children from infancy to preschool. The $\mathrm{OUCH}$ Cohort is a sample of 760 caregiver-child dyads who were videotaped over the first year of life during their routine vaccinations. Infants were included in the $\mathrm{OUCH}$ cohort if the infant had no suspected developmental delays or impairments, had no chronic illnesses, had never been admitted to a neonatal intensive care unit, and was born no more than 3 weeks preterm. It was required that caregivers could read and speak English.

The current study focuses on the 12-month vaccination wave ( $n=548)$, the preschool vaccination wave ( $n=302$; ages $4-5$ years), and the preschool assessment wave ( $n=172$; ages 4-5 years), where families agreed to participate in a full-day psychological assessment at our laboratory after their preschool vaccination. No previously published or planned/submitted manuscripts from this cohort have hypotheses or analyses that overlap with the current study. A comprehensive inventory of all $\mathrm{OUCH}$ Cohort publications can be found at www.yorku.ca/ouchlab.

Children were $47.7 \%$ female and $52.3 \%$ male, and the average age was 4.65 years $(S D=0.55)$ at the preschool vaccination. All children were considered healthy, from middle class families, lowrisk, and developmentally typical. Most children received 2 needles, but on occasion, children received 1 (6.7\%) or $3(5.1 \%)$ needles. Children (4.6\%) were given Tylenol or EMLA prior to the vaccination. Caregivers were predominantly mothers (85.1\%) with some fathers (13.9\%) and other caregivers (1.0\%). The mean age of caregivers was $39.22(\mathrm{SD}=4.12)$. Caregiver self-reported heritage culture was diverse. Caregivers (40.8\%) identified their heritage culture as European, $20.7 \%$ as Asian, $17.7 \%$ as Canadian/American, $9.2 \%$ as
Jewish, 4.8\% as African/Middle Eastern, 4.4\% as South/Latin American, and $2.4 \%$ as Other.

\subsection{Procedure}

Details of the vaccination procedure from the infant and preschool waves of the study have been published elsewhere. $^{36,39}$ Below, we describe the procedure for the preschool psychological assessment only, as this is the first publication using these data.

Caregivers who participated in the preschool vaccination were asked by a research assistant whether they would be interested in participating in the preschool assessment phase (comprised of a comprehensive battery of cognitive, psychosocial, and academic achievement). Caregivers were told that they would be provided with a psychological report from a registered psychologist (R.P.R.) and a feedback session on request. If they agreed, caregivers were contacted by phone by a research assistant to schedule the assessment within 8 weeks of the vaccination appointment. The assessment took place over a 4- to 5-hour period at the OUCH laboratory with a 1-hour lunch break. Every assessment was conducted by a qualified doctoral trainee and was supervised by the senior author (R.P.R.). Families were given a free parking voucher, a \$20.00 on-campus food voucher for lunch on the day of testing and were provided with a psychological report interpreting their findings within 3 months of the assessment.

In terms of demographic differences between caregivers who participated in the preschool time points vs caregivers who did not (age, education level, and level of acculturation), caregivers who continued at the preschool time points were slightly older (by 1 year), held a slightly higher percentage of graduate degrees (38.7\% vs 25.3\%), and had no differences in level of acculturation.

\subsection{Measures}

The measures used in both studies will be described in 5 groups: caregiver demographic information, child coping responses and coping outcomes, predictors from the 12-month vaccination (caregiver sensitivity, caregiver soothing behavior, and infant pain-related distress), predictors from the preschool vaccination (caregiver worry, caregiver sensitivity, caregiver distress-promoting and coping-promoting behavior, and child pre-needle distress), and predictors from the preschool psychological assessment (child language and executive functioning). For all measures, coders were trained to reliability by the original scale developer or by experts in the field who were trained with the scale developers. The technique of maximum likelihood estimation (described below) allowed us to include longitudinal data for all participants in our model, including those with incomplete data for certain time points or measures.

\subsubsection{Caregiver demographic information}

Caregivers were asked to complete a short demographic questionnaire that asked questions such as age, relation to the child, self-reported heritage culture, as well as child age and sex.

\subsubsection{Child coping responses and outcomes}

\subsubsection{Child coping responses-coping composite}

Child verbalizations during the vaccination were transcribed and later coded using the Child-Adult Medical Procedure 
Interaction Scale-Revised (CAMPIS-R) ${ }^{11}$ These verbalizations were making coping statements, engaging in nonprocedure-related talk, and using humor. Child engaging in audible deep breathing was also coded. Scores were summed to form a child coping response composite, which was calculated as the sum of coping behaviors divided by the total number of behaviors in a given phase. Child coping responses were coded according to three 60-second phases: (1) the 1-minute period prior to the first needle, (2) the 1 -minute period following the last needle, (3) the second 1 -minute period following the last needle.

The 3 composite scores from these phases were (1) preschooler coping responses pre-needle, (2) preschooler coping responses 1 minute, (3) preschooler coping responses 2 minutes. Higher scores reflect more child coping responses. The primary coder for the study was trained by researchers trained by the scale developer's laboratory. Interrater reliability for the CAMPIS$\mathrm{R}$ raw data was calculated using Cohen's kappa. Kappa scores ranged from 0.73 to 1.00 . The average kappa was 0.88 . Slightly over 30 percent $(n=102)$ of the 302 children seen at the preschool vaccination did not have data coded for coping responses (pre-needle, 1 and 2 minutes). While coping response recordings for these children is available, it was not feasible to code additional participants because of time and resource limitations.

\subsubsection{Child coping outcome-distress expression composite}

The child coping outcomes were operationalized as the amount of preschool pain-related distress. The Face, Legs, Activity, Cry, Consolability coding system (FLACC) ${ }^{32}$ was used to assess the degree of pain-related distress. Five categories of pain-related behaviors (face, legs, activity, cry, and consolability) were coded for four 15-second epochs immediately prior to the first needle, four 15-second epochs 1 minute after the last needle, and for four 15 -second epochs 2 minutes after the last needle. Each category was scored on a scale of 0 to 2 and then summed, which resulted in a total score between 0 and 10 for each 15 -second epoch. The four 15-second epochs were summed to form a composite score.

The 3 composite scores based on the FLACC were (1) preschooler coping outcome pre-needle, (2) preschooler coping outcome 1 minute, and (3) preschooler coping outcome 2 minutes. Because each composite was comprised of 4 total scores between 0 and 10, the total possible score for each composite was 40. Higher scores reflect poorer child coping outcome (ie, higher pain-related distress). Interrater reliability was high (all intraclass correlations exceeded 0.85 for the 5 total behavior indices). Of the 302 children seen at the preschool vaccination, 6,4 , and 7 percent did not have data for the preschooler coping outcome pre-needle, 1 minute, and 2 minutes, respectively. This was due to missing or uncodable video footage.

As established with latent growth curve analysis at the preschool vaccination, the selection of the 1-minute period following the last needle and the second 1-minute period following the last needle as separate time points for coping responses and coping outcomes was purposeful. ${ }^{48}$ This selection was made because of the importance of differentiating between reactivity and regulation. ${ }^{37}$ The first 1 -minute period following the last needle includes the preschooler's initial reactions post-needle (ie, the first 0-15 seconds and thereafter), whereas the second 1-minute period encompasses a regulatory period.

\subsubsection{Predictors from the 12-month vaccination}

\subsubsection{Caregiver sensitivity at the 12-month vaccination}

Caregiver sensitivity at the 12-month vaccination was coded using the Infancy/Early Childhood Version of the Emotional Availability Scales-Fourth Edition (EAS). ${ }^{7}$ Rather than using frequency counts of caregiver behaviors, the EAS is a global clinical judgment of caregiving behavior that is contextualized by the infant's reaction to those behaviors. The total score is a clinical judgment based on objective parameters regarding the quality of the caregiver behaviors. The EAS has been well validated in a variety of distressing nonpain-related contexts ${ }^{8}$ as well as in pain-related contexts. ${ }^{21,22,36,38}$ For a caregiver to have a high score, he or she would have to consistently enact behaviors (regardless of what those specific behaviors are) that sensitively and effectively address the infant's pain-related distress. The EAS total score sums caregiver behavior on 4 different subscales: sensitivity, structuring, nonintrusiveness, and nonhostility. Caregiver sensitivity included the caregiver's ability to interpret and respond to the infant's cues while displaying appropriate effect and respecting the developmental level of the infant (eg, sensitively and contingently responding to the infant's pain cues). Caregiver structuring referred to the caregiver's ability to structure the environment in a manner that leads the infant in a positive direction (eg, using toys to distract the baby from the pain). Caregiver nonintrusiveness referred to the caregiver's ability to be available and avoid intrusive, overstimulating, or overpowering behaviors (eg, getting in the infant's face and intrusively kissing the infant while the infant is highly distressed). Finally, caregiver nonhostility referred to the caregiver's ability to refrain from antagonistic or impatient behaviors (eg, expressing frustration about the infant's pain-related crying). The EAS rating was based on video footage from the time the caregiver and infant entered the clinic room until they left. After viewing the entire filmed interaction, a coder provided a rating on each of the emotional availability subscales (potential score ranges: 7-29). These subscales were subsequently summed to form a composite emotional availability score on a scale that potentially ranges from 28 to 116 . On all scales, higher scores represented more optimal interactions. When more than one caregiver accompanied the infant for the vaccination appointment, the caregiver who did the majority of the caregiving was coded. When both caregivers provided equal care during the clinic visit, both caregivers were coded and an average was obtained. Four coders coded the videotaped vaccination appointments for this study and were blind to study hypotheses. Interrater reliability was calculated among every permutation of the 4 coders (eg, coder A with B, B with $C, A$ with $D$, etc.). Intraclass correlations for the caregiver EAS composite score ranged from 0.80 to 0.93 . A small percentage $(<1 \%)$ of the 548 infants seen at the 12-month vaccination had missing data for caregiver sensitivity. This was due to missing or uncodable video footage.

There was no significant difference in caregiver sensitivity scores between caregivers who participated in the preschool time points and caregivers who did not.

\subsubsection{Caregiver proximal soothing and verbal reassurance at the 12-month vaccination}

Caregiver proximal soothing and verbal reassurance were coded using the Measure of Adult and Infant Soothing and Distress (MAISD). ${ }^{19}$ The MAISD obtains reliable and valid scores of behavioral observations scale and was developed to evaluate the behaviors of infants, caregivers, and health care professionals 
during painful pediatric medical procedures. ${ }^{19}$ To build the most parsimonious model possible, only 3 MAISD caregiver behaviors were used (rocking, physical comfort, verbal reassurance). Further details on our decision to use these 3 MAISD caregiver behaviors, specifically is provided below (See Data Analysis section). Seven coders, trained to reliability under supervision of the scale developer, coded the data. Interrater reliability was calculated among different permutation of coders (eg, coder A with $B, B$ with $C, A$ with $D$, etc.). The intraclass correlations ranged from 0.75 to 0.95 .

Rocking, physical comfort and verbal reassurance were all coded as either present or absent for 5 -second epochs during the following three 60-second phases: (1) the 1 minute prior to the first needle, (2) the 1 minute period following the last needle and (3) the second 1-minute period following the last needle. Index scores representing the proportion of time each behavior was present and was calculated by adding the total number of 5second epochs during which each behavior was displayed in a phase and dividing by the total number of codable epochs in the phase. The index score for each behavior is a continuous proportion score, ranging from 0 to 1 , with higher scores reflecting a greater proportion of epochs in which the behavior was present.

Physical comfort was coded when any physical (ie, nonverbal) behavior was conducted in an attempt to comfort the infant. This included rubbing, massaging, patting, hugging, or kissing the infant. Rocking was coded when the caregiver swayed, rocked, or bounced the infant.

Rocking and physical comfort were combined to create a proximal soothing variable. To obtain a composite score of caregiver proximal soothing over the 3 phases at the 12-month vaccination, the index scores for rocking and physical comfort for each phase were summed.

There was no significant difference in caregiver proximal soothing scores between caregivers who participated in the preschool time points and caregivers who did not.

Verbal reassurance was coded whenever caregivers made reassuring comments towards the infant (eg, "it is okay," "we are almost done," "it's alright, baby," "I'm sorry"). Similarly, the verbal reassurance scores for each of the 3 phases were summed to create a total verbal reassurance score for the 12-month vaccination.

A small percentage (7\%) of the 548 infants seen at the 12month vaccination had missing data for proximal soothing and verbal reassurance. This was due to missing or uncodable video footage.

Caregivers who participated at the preschool time points engaged in more verbal reassurance at the 12-month vaccination than caregivers who did not participate at the preschool time points. However, the magnitude of the difference was not considered clinically significant (ie, was less than 0.1 on a 1 -point scale).

\subsubsection{Infant pain-related distress at the 12-month vaccination}

Infant pain-related distress was coded using the Modified Behavior Pain Scale (MBPS). ${ }^{45}$ The MBPS assesses the degree of an infant's pain-related distress over 15-second epochs. Coders rate the severity of distress reflected in 3 types of infant pain behaviors (facial expression [range 0-3], crying [range 0-4], and body movement [range 0-3]) and obtain a score from 0 to 10. Two separate 15-second epochs were analyzed for this study to examine infant pain-related distress: the 1-minute period after the needle (MBPS1) and the subsequent 1-minute period after the needle (MBPS2). For the purposes of the present study, infant pain-related distress was operationalized as the sum of MBPS1 and MBPS2. Higher scores reflect greater pain expressed during the first 2 minutes after the last needle. Interrater reliability between the coders was high (intraclass correlations between 0.93 and 0.96). A small percentage (9\%) of the 548 infants seen at the 12-month vaccination had missing data for pain-related distress. This was due to missing or uncodable video footage.

Children who participated in the preschool time points had higher pain-related distress at the 12-month vaccination than children who did not continue at preschool. However, the magnitude of the difference was not considered clinically significant (ie, a difference of 0.8 on a 20 -point scale).

\subsubsection{Predictors from the preschool vaccination}

\subsubsection{Caregiver's worry pre-needle at the preschool vaccination}

While in the waiting room before the child's preschool vaccination, caregivers were asked to rate their own worry about the child's needle pain using a scale from 0 to 10 , where 0 was no worry and 10 was the most worry possible. A small percentage $(<1 \%)$ of the 302 caregivers seen at the preschool vaccination had missing data for caregiver worry. This was due to the research assistant being unable to obtain this data.

\subsubsection{Caregiver sensitivity at the preschool vaccination}

Caregiver sensitivity at the preschool vaccination was measured using The Maternal Behaviour Q-Set Short Version (MBQS). ${ }^{46}$ The MBQS is a 25-item version of the 90-item Maternal Behaviour Q-set (MBQS). ${ }^{35}$ The $25 \mathrm{MBQS}$ items tap into various features related to the construct of caregiver sensitivity including response to distress, monitoring of the child's expression of emotions and behavior, attentiveness to the child's cues, appropriateness of caregiver affect, and support in negative or distressful situations. These items are rated on a Likert-type scale from - 2 ("not at all") to +2 ("very much like") a prototypical sensitive caregiver. The final sensitivity score is a Pearson's $r$-value that is generated from the item-by-item correlation between the score derived from the caregiver's behavior and an aggregate score of a prototypically sensitive caregiver's behavior. Twenty-four percent of the 302 caregivers seen at the preschool vaccination did not have data for caregiver sensitivity. This was due to fact that data collection for the preschool vaccination continued beyond the point at which coding for caregiver sensitivity was completed.

Two coders coded MBQS ( $n=215$ ) over a 4-year period. Sixty-seven percent of videos $(n=145)$ were double-coded (ie, independently coded by the 2 coders) for reliability purposes. Scores for every case that was double coded were compared across both coders. For any case where coders' scores differed by an absolute value of 0.2 or greater, the coders met, rewatched the video, discussed the case, and reached a consensus score. Interrater reliability was strong, with an overall intraclass correlation of 0.82 .

\subsubsection{Caregiver coping-promoting and distress- promoting behaviors at the preschool vaccination}

Caregiver verbalizations during the preschool vaccination were transcribed and later coded using the Child-Adult Medical Procedure Interaction Scale-Revised (CAMPIS-R) ${ }^{11}$ to operationalize caregiver coping-promoting and distress-promoting behaviors in the models. Three caregiver verbalizations were used to 
obtain a summed composite of caregiver coping-promoting behaviors. These verbalizations were humor directed to the child, nonprocedure-related talk to the child, and command to use the coping strategy. Five caregiver verbalizations were used to obtain a summed composite of caregiver distresspromoting behaviors. These verbalizations were criticism, making a reassuring comment, giving control to the child, apologizing, and expressing empathy. Verbalizations were coded according to three 60-second phases: (1) 1 minute prior to the first needle, (2) the 1-minute period following the last needle, and (3) the 2-minute period following the last needle. Scores for caregiver coping-promoting and distress-promoting behaviors were calculated as the sum of coping-promoting and distress-promoting behaviors divided by the total number of behaviors in a given phase. The 6 composite scores of caregiver coping-promoting and distress-promoting behaviors were as follows: (1) caregiver coping-promoting behaviors 1 minute pre-needle; (2) caregiver coping-promoting behaviors 1 minute post-needle; (3) caregiver coping-promoting behaviors 2 minutes post-needle; (4) caregiver distress-promoting behaviors 1 minute pre-needle; (5) caregiver distresspromoting behaviors 1 minute post-needle; and (6) caregiver distress-promoting behaviors 2 minutes post-needle. The Observer XT (Noldus Inc.) was used to facilitate coding the video data.

Interrater reliability for the CAMPIS-R raw data was calculated using Cohen kappa. Kappa scores ranged from 0.73 to 1.00. The average kappa was 0.88 . Slightly over 30 percent of the 302 caregivers seen at the preschool vaccination did not have data for caregiver coping-promoting and distress-promoting behavior. The explanation has been previously described in the above section on child coping responses (for which the same intensive coding system was used).

\subsubsection{Child pre-needle distress at the preschool vaccination}

The Face, Legs, Activity, Cry, Consolability coding system $(\text { FLACC })^{32}$ was used to assess the degree of preschool painrelated pre-needle distress. Five types of pain-related behaviors (face, legs, activity, cry, and consolability) were coded for 15 seconds prior to the needle. Each category was scored on a scale of 0 to 2, which resulted in a total score between 0 and 10 . Interrater reliability was high (all intraclass correlations exceeded 0.85 for the 5 total behavior indices). Six percent of the 302 children seen at the preschool vaccination did not have data for pre-needle distress. This was due to missing or uncodable video footage.

\subsubsection{Predictors from the preschool psychological assessment}

\subsubsection{Preschooler executive functioning}

Preschooler's executive functioning was measured during the preschool assessment using the Behavior Rating Inventory of Executive Function-Preschool (Parent Version) (BRIEF-P). ${ }^{24}$ The BRIEF-P is a questionnaire, with established reliability and validity, for caregivers of children between 2 and 5 years of age that evaluates executive function challenges in preschoolers. Executive functioning is an overarching term that refers to neuropsychological processes that enable physical, cognitive, and emotional self-control, ${ }^{20}$ constructs critical to both coping responses and outcomes. The BRIEF-P provides scores on 5 domains of potential challenge with executive function (inhibition, shifting, emotional control, working memory, and planning/ organizing) and a Global Executive Composite T-score. The composite was used for analyses in the present study. Higher scores reflect higher executive functioning challenges. Two percent of the 172 children seen at the preschool assessment did not have data for executive functioning. This was due to a small handful of parents not completing the questionnaire.

\subsubsection{Preschooler language}

Preschooler's language ability was measured during the preschool assessment using the General Language Composite (GLC) of the Wechsler Preschool and Primary Scale of Intelligence-Third Edition (WPPSI-III). ${ }^{49}$ This is a gold standard battery in the field of child assessment, with established validity and reliability. The WPPSI-III is a commonly used intelligence test for preschool children ages 2.6 to 7.3 years. The GLC is derived from a child's scores on the receptive vocabulary subtest (ie, how well they understand words) and picture naming subtest (ie, how well they can express words) on the WPPSI-III. This composite was selected because the coping response was in essence a measure of coping language. A standard score is provided with a mean of 100 and a standard deviation of 15 . Higher scores reflect higher language ability. Four percent of the 172 children seen at the preschool assessment did not have data for language ability. This was due to a small handful of parent-child dyads being unable to complete the entire assessment.

\subsection{Data analysis}

\subsubsection{Study 1: the relationships between preschool children's coping responses and outcomes in the vaccination context}

To simultaneously address reciprocal influences on coping responses and coping outcomes, an autoregressive crosslagged path model (eg, Ref. 27) (Fig. 1) was fitted to the data using structural equation modeling software. This model included parameters such that for both child coping responses and child coping outcomes, 3 types of relationships were examined simultaneously: (1) the prediction of each child coping response composite (or child coping outcome composite) from the child coping response composite (or child coping outcome composite) that directly preceded it (eg, child coping response composite pre-needle predicting child coping response composite at 1 minute); (2) the prediction of each child coping outcome composite (or child coping response composite) from the child coping response composite (or child coping outcome composite) that directly preceded it (eg, child coping response composite at 1 minute at predicting child coping outcome composite at 2 minutes); and (3) the concurrent residual relationships between child coping responses and child coping outcomes at each of the 3 different 60-second phases within the vaccination appointment (eg, child coping responses pre-needle with child coping outcomes pre-needle).

\subsubsection{Study 2: preschool children's coping responses and outcomes in the vaccination context: caregiver and child predictors from infancy and preschool}

Four path models (Figs. 2-5) were fitted to the data using structural equation modeling software. When testing hypotheses pertaining to antecedent-consequence relationships, such as those in the present study, path analysis is considered an optimal 


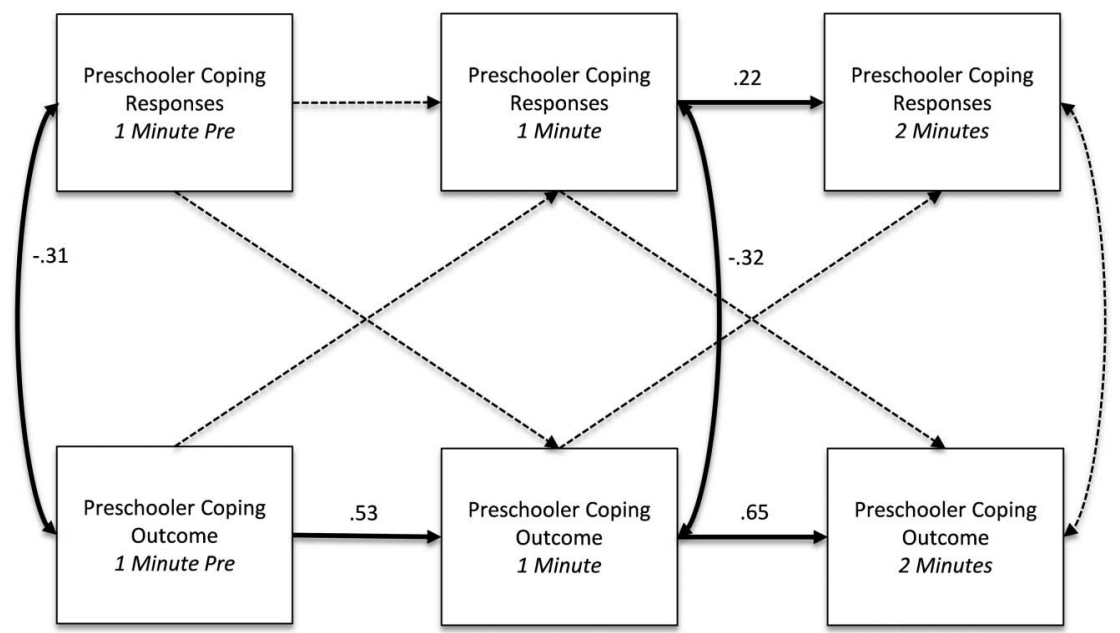

Figure 1. Autoregressive cross-lagged path model: relationships between preschool children's coping responses and outcomes. Solid paths and the corresponding. correlations/standardized parameter estimates are significant at $P<0.05$. Dotted paths represent hypothesized pathways that are nonsignificant.

method of choice. ${ }^{13,31}$ The first 2 path analyses examined infant and preschool variables predicting preschooler coping responses at 1 and 2 minutes post-needle. The third and fourth path analyses were similar with 1 exception. In path models 3 and 4 , preschooler coping outcomes at 1 and 2 minutes post-needle were the dependent variables of interest.

Finally, for each model, the preschool caregiver behaviors (coping-promoting, distress-promoting) and preschooler distress behaviors (ie, FLACC) used as predictors pertained to the time epoch directly preceding the dependent variable. Thus, model 1 and model 3 used variables from the preschool pre-needle epoch (to predict preschooler coping responses and outcomes at 1 minute, respectively) and model 2 and 4 used variables from the preschool 1-minute epoch (to predict preschooler coping responses and outcomes at 2 minute, respectively). In terms of entering child distress behaviors from the directly preceding time epoch into the models, this choice was made because a critical assumption in creating the path models was that young children's pain responding during painful procedures has been established to predict subsequent pain responding to that procedure. 1,17,25 Thus, all path models included a predictor variable of preschooler's pain-related distress from the closest time point preceding each dependent variable of interest. To parallel this, the same was done with both coping-promoting and distresspromoting caregiver variables. Correlations among all potential predictor variables were first examined for all 4 models to determine which relationships between predictors to include in the final path models.

Based on previous research on the MAISD behaviors at the 12month vaccination, ${ }^{30}$ the 4 most commonly occurring caregiver behaviors were selected a priori for our path models: rocking, physical comfort, verbal reassurance, and distraction. These 4 behaviors were selected (as opposed to all 8 behaviors on the scale) to create the most parsimonious model possible. However,

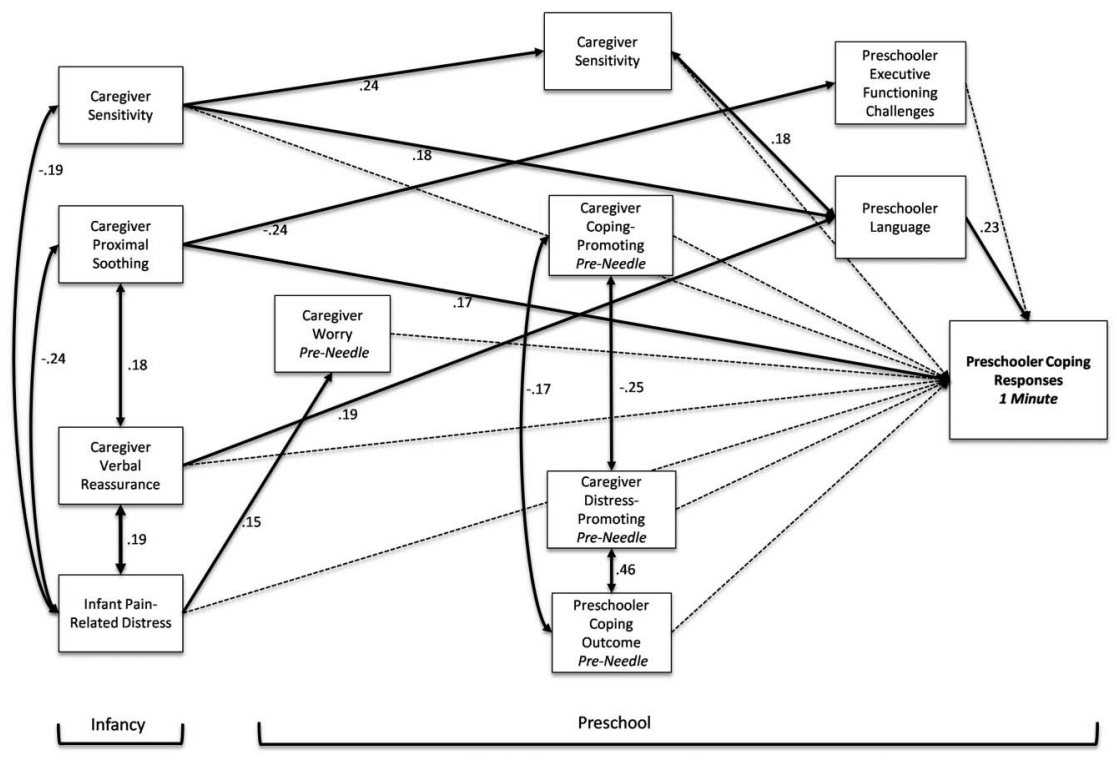

Figure 2. Model 1: predicting preschool coping responses at 1 minute post-vaccination from infant and preschool predictors. Solid paths and the corresponding correlations/standardized parameter estimates are significant at $P<0.05$. Dotted paths represent hypothesized pathways that are non-significant. 


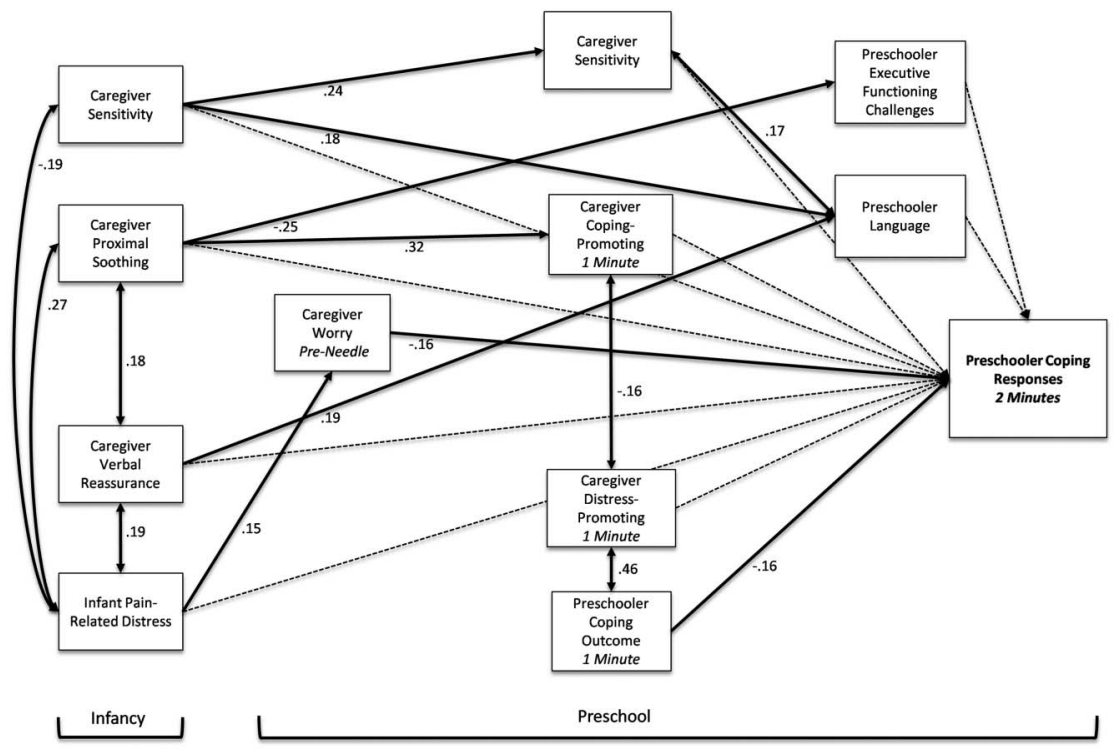

Figure 3. Model 2: predicting preschool coping responses at 2 minutes post-vaccination from infant and preschool predictors. Solid highlighted paths and the corresponding correlations/standardized parameter estimates are significant at $P<0.05$. Dotted paths represent hypothesized pathways that are nonsignificant.

the caregiver behavior of distraction was not included in our final models because this variable was not correlated with any other variables in the model and was impacting model fit. The pattern of relationships in the model did not change after removing the distraction variable.

All data analyses were conducted using Amos Version 19.0 statistical software. ${ }^{3}$ To maximize information used in this study's analyses, direct maximum likelihood estimation ${ }^{2}$ was used so that all cases, including those with missing data or without data for all 3 time points (ie, 12-month vaccination, preschool vaccination, and preschool assessment), contributed to model estimation. Goodness of fit for all models was evaluated using the $\chi^{2}$ significance test $(\alpha=0.05)$, the comparative fit index $(\mathrm{CFI}),{ }^{5}$ and the root mean square error of approximation (RMSEA). ${ }^{44}$ Comparative fit index values of 0.95 or higher and RMSEA values of 0.06 or less indicate that a model provides a good fit for the data. ${ }^{26}$

\subsubsection{Study 2: post hoc analyses}

Our path analyses unexpectedly indicated that with the exception of caregiver coping-promoting behaviors at 1 minute post-needle at the preschool vaccination positively predicting the preschooler coping outcome at 2 minutes post-needle, caregiver copingpromoting, and distress-promoting behaviors did not significantly predict subsequent preschooler coping responses or outcomes.

Accordingly, a series of post hoc correlations were run to determine whether concurrent relationships between these variables existed (ie, when these caregiver and preschooler variables were measured at the same point in time). While the

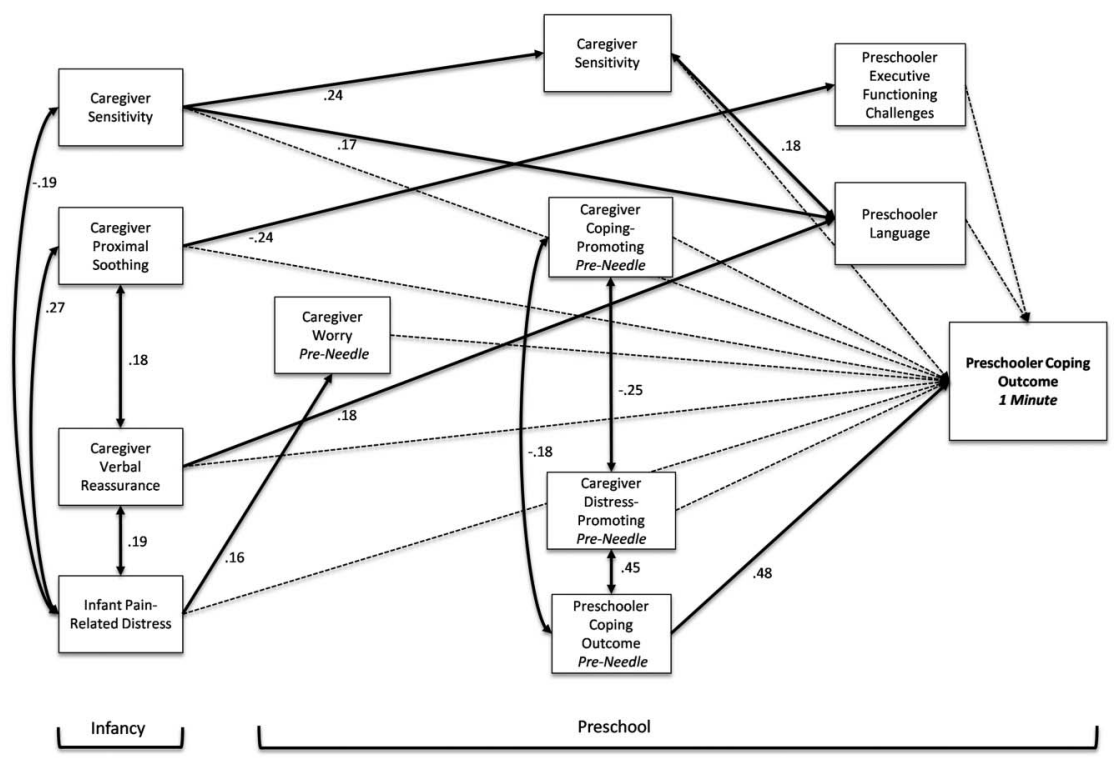

Figure 4. Model 3: predicting preschool coping outcomes at 1 minute post-vaccination from infant and preschool predictors. Solid highlighted paths and the corresponding correlations/standardized parameter estimates are significant at $P<0.05$. Dotted paths represent hypothesized pathways that are nonsignificant. 


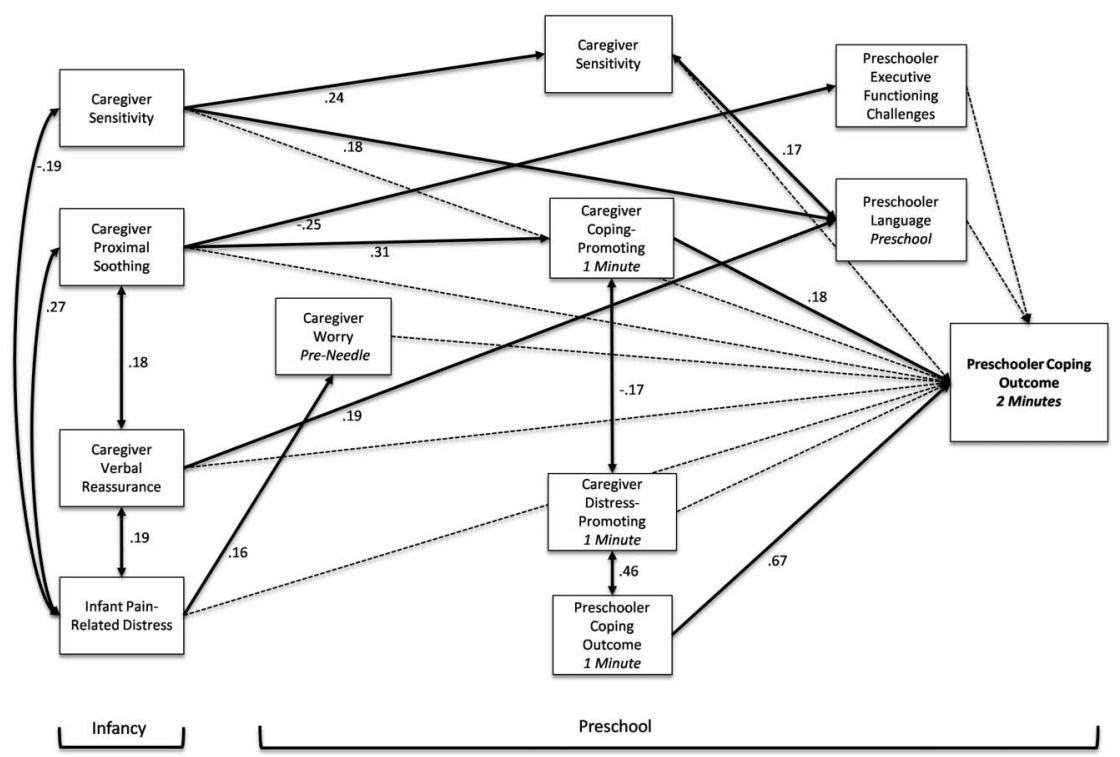

Figure 5. Model 4: predicting preschool coping outcomes at 2 minutes post-vaccination from infant and preschool predictors. Solid highlighted paths and the corresponding correlations/standardized parameter estimates are significant at $P<0.05$. Dotted paths represent hypothesized pathways that are nonsignificant.

research questions in the current study pertained to the nonconcurrent relationships examined in the path models (ie, the relationships between caregiver variables that precede children's coping variables in time and those children's coping variables), the decision to conduct these post hoc correlations was made in an attempt to comprehensively explore the potential processes involved in coping in our sample.

\section{Results}

\subsection{Study 1: the relationships between preschool children's} coping responses and outcomes in the vaccination context

The autoregressive cross-lagged path model was estimated (Fig. 1). The nonsignificant $\chi^{2}$ test of overall model fit $\left(\chi^{2}=0.41, d f=4\right.$, $P=0.98)$ and the combination of other fit indices (CFI = 1.00; RMSEA < 0.001) suggested that the model fit the data well. Standardized estimates of significant pathways are reported in the figure. Table 1 presents the overall mean values and SDs of all model variables, and Table 2 presents the standard bivariate correlations among all model variables. All standardized and unstandardized estimates are reported in Table 3.

The results will now turn to reporting pathway findings. For conceptual coherence, they will be organized according to the 5 hypotheses. Standardized estimates are reported in the text.

\subsubsection{Hypothesis 1: preceding coping responses would positively predict subsequent coping responses within the postneedle phases of the procedure}

Preschooler coping responses preneedle did not predict preschooler coping responses at 1 minute $(B=0.08, P=0.280)$. Preschooler coping responses at 1 minute positively predicted preschooler coping responses at 2 minutes $(B=0.22, P=0.002)$.

\subsubsection{Hypothesis 2: preceding coping outcomes would positively predict subsequent coping outcomes across all phases of the procedure}

Preschooler coping outcomes pre-needle positively predicted preschooler coping outcomes at 1 minute $(B=0.53, P<$
0.001). Preschooler coping outcomes at 1 minute positively predicted preschooler coping outcomes at 2 minutes $(B=0.65$, $P<0.001)$.

\subsubsection{Hypothesis 3: concurrent coping responses and coping outcomes would be negatively related}

Preschooler coping responses pre-needle were negatively related to preschooler coping outcomes pre-needle $(B=-0.31$, $P<0.001$ ). Preschooler coping responses at 1 minute were negatively related to preschooler coping outcomes at 1 minute $(B=-0.32, P<0.001)$. Preschooler coping responses at 2 minutes were not significantly related to preschooler coping outcomes at 2 minutes $(B=-0.10, P=0.198)$.

\subsubsection{Hypothesis 4: preceding coping responses would negatively predict subsequent coping outcomes}

Preschooler coping responses pre-needle did not significantly predict preschooler coping outcomes at 1 minute $(B=0.07, P=$ 0.285). Preschooler coping responses at 1 minute did not significantly predict preschooler coping outcomes at 2 minutes (B=-0.02, $P=0.695)$.

\subsubsection{Hypothesis 5: preceding coping outcomes would negatively predict subsequent coping responses}

Preschooler coping outcomes pre-needle did not significantly predict preschooler coping responses at 1 minute $(B=-0.12$, $P=0.111)$. Preschooler coping outcomes at 1 minute did not predict preschooler coping responses at 2 minutes $(B=-0.09$, $P=0.206)$.

\subsection{Study 2: preschool children's coping responses and outcomes in the vaccination context: caregiver and child predictors from infancy and preschool}

Four separate path models were estimated as described above (Figs. 2-5). Standardized estimates of significant pathways are 
Table 1

\section{Overall mean values and SDs of all model variables.}

\begin{tabular}{|c|c|c|c|c|}
\hline & $\mathbf{N}$ & Mean & SD & Scale range \\
\hline Caregiver sensitivity (infancy) & 546 & 92.77 & 11.03 & $28-116$ \\
\hline Caregiver proximal soothing (infancy) & 510 & 1.52 & 1.21 & $0-2$ \\
\hline Caregiver verbal reassurance (infancy) & 509 & 0.42 & 0.45 & $0-1$ \\
\hline Infant pain-related distress & 496 & 10.35 & 4.41 & $0-20$ \\
\hline Caregiver worry pre-needle (preschool) & 300 & 2.28 & 2.71 & $0-10$ \\
\hline Caregiver sensitivity (preschool) & 229 & 0.32 & 0.41 & $0-1$ \\
\hline Caregiver CP behaviors pre-needle (preschool) & 203 & 0.29 & 0.28 & $0-1$ \\
\hline Caregiver DP behaviors pre-needle (preschool) & 199 & 0.10 & 0.14 & $0-1$ \\
\hline Preschooler coping response pre-needle & 203 & 0.22 & 0.34 & $0-1$ \\
\hline Preschooler coping outcome pre-needle & 284 & 7.38 & 9.84 & $0-10$ \\
\hline Preschooler executive functioning & 169 & 48.30 & 9.56 & $0-100$ \\
\hline Preschooler language & 165 & 107.44 & 13.82 & $40-160$ \\
\hline Preschooler coping responses $1 \mathrm{~min}$ & 203 & 0.20 & 0.33 & $0-1$ \\
\hline Caregiver CP behaviors 1 min (preschool) & 203 & 0.10 & 0.14 & $0-1$ \\
\hline Caregiver DP behaviors 1 min (preschool) & 203 & 0.16 & 0.16 & $0-1$ \\
\hline Preschooler coping outcome $1 \mathrm{~min}$ & 290 & 13.84 & 10.00 & $0-10$ \\
\hline Preschooler coping responses $2 \mathrm{~min}$ & 203 & 0.23 & 0.33 & \\
\hline Preschooler coping outcome 2 min & 281 & 5.62 & 7.52 & $0-10$ \\
\hline
\end{tabular}

reported in the figures. Table 1 presents the overall mean values and SDs of all model variables. Table 2 presents the bivariate correlations among all model variables. All standardized and unstandardized estimates are reported in accompanying tables

\section{(Tables 4-7)}

Of note, prior to estimating the models, the bivariate correlations among all model variables were first examined. When it was indicated that there was not a bivariate relationship between 2 predictor variables, this relationship was not included in the path model. Finally, a requirement of structural equation modeling is that, regardless of relationships of interest in one's study, if a meaningful relationship exists between 2 variables, this relationship must be accounted for in the analysis to ensure model fit. Thus, the various significant relationships among the variables from the 12-month vaccination were accounted for in the models but because they have been previously examined and reported, ${ }^{4,17,36,38}$ they were not of interest and will not be described in the text below.

\subsection{Path models}

\subsubsection{Overall model fit and accounted for variance}

Model 1 examined infant and preschool predictors of preschooler's coping responses at 1 minute post-needle. The nonsignificant $\chi^{2}$ test of overall model fit $\left(\chi^{2}=40.22, d f=42\right.$, $P=0.55)$ and the combination of other fit indices (CFI = 1.00; RMSEA < 0.001) suggested that Model 1 fit the data well. Figure 2 provides the corresponding model diagram (along with significant standardized parameter estimates) and Table 4 presents all standardized and unstandardized parameter estimates. The set of predictors in model 1 accounted for $12 \%$ of the variance $\left(R^{2}\right)$ in preschooler's coping responses at 1 minute post-needle.
Model 2 examined infant and preschool predictors of preschooler's coping responses at 2 minutes post-needle. The nonsignificant $\chi^{2}$ test of overall model fit $\left(\chi^{2}=30.77, d f=\right.$ $42, P=0.90)$ and the combination of other fit indices (CFI = 1.00; RMSEA < 0.001) suggested that model 2 fit the data well. Figure 3 provides the corresponding model diagram (along with significant standardized parameter estimates), and Table 5 presents all standardized and unstandardized parameter estimates. The set of predictors in model 2 accounted for $11 \%$ of the variance $\left(R^{2}\right)$ in preschooler's coping responses at 2 minutes post-needle.

Model 3 examined infant and preschool predictors of the preschooler's coping outcome at 1 minute post-needle. The nonsignificant $\chi^{2}$ test of overall model fit $\left(\chi^{2}=39.68, d f=42, P=\right.$ 0.57 ) and the combination of other fit indices (CFI = 1.00; RMSEA $<0.001$ ) suggested that Model 3 fit the data well. Figure 4 provides the corresponding model diagram (along with significant standardized parameter estimates), and Table 6 presents all standardized and unstandardized parameter estimates. The set of predictors in model 3 accounted for $29 \%$ of the variance $\left(R^{2}\right)$ in the oreschooler coping outcome at 1 minute post-needle.

Model 4 examined infant and preschool predictors of the preschooler's coping outcome at 2 minutes post-needle. The nonsignificant $\chi^{2}$ test of overall model fit $\left(\chi^{2}=31.03, d f=42, P=\right.$ 0.89 ) and the combination of other fit indices (CFI = 1.00; RMSEA $<0.001$ ) suggested that model 4 fit the data well. Figure 5 provides the corresponding model diagram (along with significant standardized parameter estimates) and Table 7 presents all standardized and unstandardized parameter estimates. The set of predictors in model 4 accounted for $48 \%$ of the variance $\left(R^{2}\right)$ in the Preschooler Coping Outcome at 2 minutes post-needle.

The results will now turn to reporting pathway findings over the 4 models. Standardized estimates are reported in the text. For conceptual coherence, they will be organized according to the 
Table 2

Bivariate correlations among all model variables.

\begin{tabular}{|c|c|c|c|c|c|c|c|c|c|c|c|c|c|c|c|c|c|}
\hline & 12 & 3 & 4 & 5 & 6 & 7 & 8 & 9 & 10 & 11 & 12 & 13 & 14 & 15 & 16 & 17 & 18 \\
\hline 1. Caregiver sensitivity (infancy) & $\begin{array}{ll}1 & 0.03 \\
& (0.467)\end{array}$ & $\begin{array}{l}-0.05 \\
(0.291)\end{array}$ & $\begin{array}{l}-0.20^{*} \\
(0.000)\end{array}$ & $\begin{array}{l}0.02 \\
(0.749)\end{array}$ & $\begin{array}{l}0.24 \dagger \\
(0.001)\end{array}$ & $\begin{array}{l}0.01 \\
(0.887)\end{array}$ & $\begin{array}{l}0.17 \ddagger \\
(0.041)\end{array}$ & $\begin{array}{l}0.11 \\
(0.134)\end{array}$ & $\begin{array}{l}0.00 \\
(0.957)\end{array}$ & NA & $\begin{array}{l}-0.09 \\
(0.172)\end{array}$ & $\begin{array}{l}0.11 \\
(0.157)\end{array}$ & $\begin{array}{l}0.01 \\
(0.886)\end{array}$ & $\begin{array}{l}0.02 \\
(0.831)\end{array}$ & $\begin{array}{l}0.01 \\
(0.860)\end{array}$ & $\begin{array}{l}-0.04 \\
(0.576)\end{array}$ & $\begin{array}{l}0.02 \\
(0.809)\end{array}$ \\
\hline $\begin{array}{l}\text { 2. Caregiver proximal soothing } \\
\text { (infancy) }\end{array}$ & 1 & $\begin{array}{l}0.18 \dagger \\
(0.000)\end{array}$ & $\begin{array}{l}0.27 \dagger \\
(0.000)\end{array}$ & $\begin{array}{l}0.08 \\
(0.223)\end{array}$ & $\begin{array}{l}0.11 \\
(0.123)\end{array}$ & $\begin{array}{l}-0.25 \dagger \\
(0.003)\end{array}$ & $\begin{array}{l}0.12 \\
(0.157)\end{array}$ & $\begin{array}{l}0.00 \\
(0.987)\end{array}$ & $\begin{array}{l}-0.00 \\
(0.977)\end{array}$ & NA & $\begin{array}{l}-0.06 \\
(0.385)\end{array}$ & $\begin{array}{l}0.18 \ddagger \\
(0.020)\end{array}$ & $\begin{array}{l}0.29^{*} \\
(0.000)\end{array}$ & $\begin{array}{l}-0.04 \\
(0.643)\end{array}$ & $\begin{array}{l}-0.02 \\
(0.810)\end{array}$ & $\begin{array}{l}0.12 \\
(0.111)\end{array}$ & $\begin{array}{l}0.09 \\
(0.165)\end{array}$ \\
\hline $\begin{array}{l}\text { 3. Caregiver verbal reassurance } \\
\text { (infancy) }\end{array}$ & & 1 & $\begin{array}{l}0.20^{*} \\
(0.000)\end{array}$ & $\begin{array}{l}0.06 \\
(0.319)\end{array}$ & $\begin{array}{l}0.07 \\
(0.339)\end{array}$ & $\begin{array}{l}-0.11 \\
(0.180)\end{array}$ & $\begin{array}{l}0.21 \ddagger \\
(0.013)\end{array}$ & $\begin{array}{l}0.04 \\
(0.593)\end{array}$ & $\begin{array}{l}0.02 \\
(0.784)\end{array}$ & NA & $\begin{array}{l}-0.05 \\
(0.438)\end{array}$ & $\begin{array}{l}0.10 \\
(0.180)\end{array}$ & $\begin{array}{l}0.06 \\
(0.425)\end{array}$ & $\begin{array}{l}0.03 \\
(0.727) \\
\end{array}$ & $\begin{array}{l}0.02 \\
(0.807) \\
\end{array}$ & $\begin{array}{l}0.19 \ddagger \\
(0.015)\end{array}$ & $\begin{array}{l}-0.04 \\
(0.574)\end{array}$ \\
\hline 4. Infant pain-related distress & & & 1 & $\begin{array}{l}0.16 \ddagger \\
(0.018) \\
\end{array}$ & $\begin{array}{l}-0.06 \\
(0.403) \\
\end{array}$ & $\begin{array}{l}-0.03 \\
(0.704) \\
\end{array}$ & $\begin{array}{l}-0.03 \\
(0.712) \\
\end{array}$ & $\begin{array}{l}-0.06 \\
(0.489) \\
\end{array}$ & $\begin{array}{l}0.11 \\
(0.170) \\
\end{array}$ & NA & $\begin{array}{l}0.03 \\
(0.690) \\
\end{array}$ & $\begin{array}{l}0.02 \\
(0.804) \\
\end{array}$ & $\begin{array}{l}0.05 \\
(0.506) \\
\end{array}$ & $\begin{array}{l}-0.11 \\
(0.197) \\
\end{array}$ & $\begin{array}{l}-0.02 \\
(0.765) \\
\end{array}$ & $\begin{array}{l}0.13 \\
(0.119) \\
\end{array}$ & $\begin{array}{l}-0.02 \\
(0.780) \\
\end{array}$ \\
\hline $\begin{array}{l}\text { 5. Caregiver worry pre-needle } \\
\text { (preschool) }\end{array}$ & & & & 1 & $\begin{array}{l}0.05 \\
(0.415) \\
\end{array}$ & $\begin{array}{l}0.15 \\
(0.069) \\
\end{array}$ & $\begin{array}{l}-0.10 \\
(0.206) \\
\end{array}$ & $\begin{array}{l}0.05 \\
(0.474) \\
\end{array}$ & $\begin{array}{l}0.00 \\
(0.969) \\
\end{array}$ & NA & $\begin{array}{l}0.03 \\
(0.581) \\
\end{array}$ & $\begin{array}{l}-0.01 \\
(0.933) \\
\end{array}$ & $\begin{array}{l}0.03 \\
(0.630) \\
\end{array}$ & $\begin{array}{l}-0.03 \\
(0.706) \\
\end{array}$ & $\begin{array}{l}0.05 \\
(0.386) \\
\end{array}$ & $\begin{array}{l}-0.14 \ddagger \\
(0.046)\end{array}$ & $\begin{array}{l}0.07 \\
(0.276) \\
\end{array}$ \\
\hline 6. Caregiver sensitivity (preschool) & & & & & 1 & $\begin{array}{l}-0.10 \\
(0.225) \\
\end{array}$ & $\begin{array}{l}0.22 \dagger \\
(0.008) \\
\end{array}$ & $\begin{array}{l}0.13 \\
(0.069) \\
\end{array}$ & $\begin{array}{l}0.10 \\
(0.177) \\
\end{array}$ & NA & $\begin{array}{l}-0.07 \\
(0.306) \\
\end{array}$ & $\begin{array}{l}0.13 \\
(0.069) \\
\end{array}$ & $\begin{array}{l}0.05 \\
(0.519) \\
\end{array}$ & $\begin{array}{l}0.05 \\
(0.546) \\
\end{array}$ & $\begin{array}{l}-0.09 \\
(0.187) \\
\end{array}$ & $\begin{array}{l}0.10 \\
(0.189) \\
\end{array}$ & $\begin{array}{l}-0.04 \\
(0.556) \\
\end{array}$ \\
\hline $\begin{array}{l}\text { 7. Preschooler executive } \\
\text { functioning }\end{array}$ & & & & & & 1 & $\begin{array}{l}-0.08 \\
(0.330) \\
\end{array}$ & $\begin{array}{l}-0.07 \\
(0.447) \\
\end{array}$ & $\begin{array}{l}0.02 \\
(0.876) \\
\end{array}$ & NA & $\begin{array}{l}0.15 \\
(0.062) \\
\end{array}$ & $\begin{array}{l}-0.01 \\
(0.896) \\
\end{array}$ & $\begin{array}{l}0.00 \\
(0.987) \\
\end{array}$ & $\begin{array}{l}-0.06 \\
(0.529) \\
\end{array}$ & $\begin{array}{l}0.13 \\
(0.114) \\
\end{array}$ & $\begin{array}{l}-0.09 \\
(0.340) \\
\end{array}$ & $\begin{array}{l}0.01 \\
(0.871) \\
\end{array}$ \\
\hline 8. Preschooler language & & & & & & & 1 & $\begin{array}{l}0.12 \\
(0.232)\end{array}$ & $\begin{array}{l}-0.03 \\
(0.763)\end{array}$ & NA & $\begin{array}{l}0.03 \\
(0.730)\end{array}$ & $\begin{array}{l}0.28 \dagger \\
(0.003)\end{array}$ & $\begin{array}{l}0.12 \\
(0.226)\end{array}$ & $\begin{array}{l}-0.07 \\
(0.469)\end{array}$ & $\begin{array}{l}-0.09 \\
(0.300)\end{array}$ & $\begin{array}{l}0.15 \\
(0.127)\end{array}$ & $\begin{array}{l}-0.01 \\
(0.931)\end{array}$ \\
\hline $\begin{array}{l}\text { 9. Caregiver CP behaviors pre- } \\
\text { needle (preschool) }\end{array}$ & & & & & & & & 1 & $\begin{array}{l}-0.24 \dagger \\
(0.001)\end{array}$ & NA & $\begin{array}{l}-0.15 \ddagger \\
(0.037) \\
\end{array}$ & $\begin{array}{l}0.09 \\
(0.183)\end{array}$ & NA & NA & $\begin{array}{l}-0.10 \\
(0.168)\end{array}$ & NA & NA \\
\hline $\begin{array}{l}\text { 10. Caregiver DP behaviors pre- } \\
\text { needle (preschool) }\end{array}$ & & & & & & & & & 1 & & $\begin{array}{l}0.42 \dagger \\
(0.000)\end{array}$ & $\begin{array}{l}-0.08 \\
(0.248)\end{array}$ & NA & NA & $\begin{array}{l}0.29^{*} \\
(0.000)\end{array}$ & NA & NA \\
\hline $\begin{array}{l}\text { 11. Preschooler coping responses } \\
\text { pre-needle }\end{array}$ & & & & & & & & & & 1 & & $\begin{array}{l}-0.29^{\star} \\
(0.000) \\
\end{array}$ & $\begin{array}{l}0.11 \\
(0.105) \\
\end{array}$ & NA & NA & $\begin{array}{l}-0.10 \\
(0.192) \\
\end{array}$ & NA \\
\hline $\begin{array}{l}\text { 12. Preschooler coping outcome } \\
\text { pre-needle }\end{array}$ & & & & & & & & & & & 1 & $\begin{array}{l}-0.15 \ddagger \\
(0.045) \\
\end{array}$ & NA & NA & $\begin{array}{l}0.51^{*} \\
(0.000) \\
\end{array}$ & NA & NA \\
\hline $\begin{array}{l}\text { 13. Preschooler coping responses } \\
1 \mathrm{~min}\end{array}$ & & & & & & & & & & & & 1 & NA & NA & $\begin{array}{l}-0.33^{*} \\
(0.000) \\
\end{array}$ & $\begin{array}{l}0.26^{*} \\
(0.000) \\
\end{array}$ & $\begin{array}{l}-0.24 \dagger \\
(0.001)\end{array}$ \\
\hline $\begin{array}{l}\text { 14. Caregiver CP behaviors } 1 \mathrm{~min} \\
\text { (preschool) }\end{array}$ & & & & & & & & & & & & & 1 & $\begin{array}{l}-0.15 \ddagger \\
(0.034)\end{array}$ & $\begin{array}{l}0.05 \\
(0.505)\end{array}$ & $\begin{array}{l}0.13 \\
(0.073)\end{array}$ & $\begin{array}{l}0.23 \dagger \\
(0.002)\end{array}$ \\
\hline $\begin{array}{l}\text { 15. Caregiver DP behaviors } 1 \text { min } \\
\text { (preschool) }\end{array}$ & & & & & & & & & & & & & & 1 & $\begin{array}{l}0.45^{*} \\
(0.000) \\
\end{array}$ & $\begin{array}{l}-0.09 \\
(0.220) \\
\end{array}$ & $\begin{array}{l}0.25^{*} \\
(0.000) \\
\end{array}$ \\
\hline $\begin{array}{l}\text { 16. Preschooler coping outcome } 1 \\
\text { min }\end{array}$ & & & & & & & & & & & & & & & 1 & $\begin{array}{l}-0.16 \ddagger \\
(0.030)\end{array}$ & $\begin{array}{l}0.66^{*} \\
(0.000) \\
\end{array}$ \\
\hline $\begin{array}{l}\text { 17. Preschooler coping responses } \\
2 \mathrm{~min}\end{array}$ & & & & & & & & & & & & & & & & 1 & $\begin{array}{l}-0.18 \ddagger \\
(0.015)\end{array}$ \\
\hline $\begin{array}{l}\text { 18. Preschooler coping outcome } 2 \\
\text { min (preschool) }\end{array}$ & & & & & & & & & & & & & & & & & 1 \\
\hline \multicolumn{18}{|c|}{$\begin{array}{l}P \text { values are in parentheses. } \\
\text { NA refers to relationships that were not examined within any model. } \\
\star P<0.001 \text { (2 tailed). } \\
+P<0.01 \text {. } \\
\neq P<0.05 \text {. } \\
\neq P, \text { coping-promoting; DP, distress-promoting. }\end{array}$} \\
\hline
\end{tabular}




\section{Table 3}

Standardized and unstandardized estimates: autoregressive cross-lagged path model: relationships between preschool children's coping responses and outcomes.

\begin{tabular}{|c|c|c|c|c|}
\hline & Standardized estimate & Unstandardized estimate & $\mathbf{z}$ & $P, 2$ tailed \\
\hline $\begin{array}{l}\text { Preschooler coping responses pre-needle } \\
\text { Preschooler coping outcome pre-needle }\end{array}$ & -0.31 & -1.05 & -4.23 & $<0.001$ \\
\hline $\begin{array}{l}\text { Preschooler coping responses } 1 \text { min } \\
\text { Preschooler coping responses pre-needle } \\
\text { Preschooler coping outcomes pre-needle }\end{array}$ & $\begin{array}{r}0.08 \\
-0.12 \\
\end{array}$ & $\begin{array}{r}0.07 \\
-0.00 \\
\end{array}$ & $\begin{array}{r}1.08 \\
-1.59 \\
\end{array}$ & $\begin{array}{l}0.280 \\
0.111\end{array}$ \\
\hline $\begin{array}{l}\text { Preschooler coping responses } 2 \text { min } \\
\text { Preschooler coping responses } 1 \mathrm{~min} \\
\text { Preschooler coping outcomes } 1 \mathrm{~min} \\
\end{array}$ & $\begin{array}{r}0.22 \\
-0.09 \\
\end{array}$ & $\begin{array}{r}0.23 \\
-0.00 \\
\end{array}$ & $\begin{array}{r}3.11 \\
-1.27 \\
\end{array}$ & $\begin{array}{l}0.002 \\
0.206 \\
\end{array}$ \\
\hline $\begin{array}{l}\text { Preschooler coping outcomes pre-needle } \\
\text { Preschooler coping responses pre-needle }\end{array}$ & -0.31 & -1.05 & -4.23 & $<0.001$ \\
\hline $\begin{array}{l}\text { Preschooler coping outcomes } 1 \text { min } \\
\text { Preschooler coping responses pre-needle } \\
\text { Preschooler coping outcomes pre-needle } \\
\text { Preschooler coping responses } 1 \text { min }\end{array}$ & $\begin{array}{r}0.07 \\
0.53 \\
-0.32 \\
\end{array}$ & $\begin{array}{r}2.00 \\
0.54 \\
-0.87 \\
\end{array}$ & $\begin{array}{r}1.07 \\
9.66 \\
-4.32 \\
\end{array}$ & $\begin{array}{r}0.285 \\
<0.001 \\
<0.001 \\
\end{array}$ \\
\hline $\begin{array}{l}\text { Preschooler coping outcomes } 2 \text { min } \\
\text { Preschooler coping responses } 1 \text { min } \\
\text { Preschooler coping outcomes } 1 \text { min } \\
\text { Preschooler coping responses } 2 \text { min }\end{array}$ & $\begin{array}{r}-0.02 \\
0.65 \\
-0.10\end{array}$ & $\begin{array}{r}-0.54 \\
0.49 \\
-0.17\end{array}$ & $\begin{array}{r}-0.39 \\
13.01 \\
-1.29\end{array}$ & $\begin{array}{r}0.695 \\
<0.001 \\
0.198\end{array}$ \\
\hline
\end{tabular}

4 overarching hypotheses that set up the analysis a priori. Only significant relationships will be described, but all tested relationships appear in the figures and tables.

\subsubsection{Caregiver behavior during 12-month vaccination to caregiver behavior during preschool vaccination to preschooler vaccination behavior pathways}

Caregiver sensitivity at the 12-month vaccination positively predicted caregiver sensitivity at the preschool vaccination $(B=$
0.24, $P<0.001)$ across the 4 models. Caregiver sensitivity (preschool vaccination) did not in turn directly predict any of the child behavior-dependent variables across the 4 models (coping responses or coping outcomes).

Caregiver proximal soothing at the 12-month vaccination positively predicted caregiver coping-promoting behaviors at 1 minute post-needle in model 2 and model $4(B=0.32, P<0.001$; $B=0.31, P<0.001$, respectively). In turn, model 4 displayed that coping-promoting behaviors at 1 minute post-needle predicted higher coping outcome scores at 2 minutes post-needle.

\section{Table 4}

Standardized and unstandardized estimates for model 1: predicting preschool coping responses at 1 min post-vaccination from infant and preschool predictors.

\begin{tabular}{|c|c|c|c|c|}
\hline & Standardized estimate & Unstandardized estimate & $\mathbf{z}$ & $P, 2$ tailed \\
\hline \multicolumn{5}{|l|}{ Preschooler coping responses $1 \mathrm{~min}$} \\
\hline Caregiver sensitivity (infancy) & 0.03 & 0.00 & 0.44 & 0.662 \\
\hline Caregiver proximal soothing (infancy) & 0.17 & 0.05 & 2.10 & 0.036 \\
\hline Caregiver verbal reassurance (infancy) & 0.01 & 0.01 & 0.13 & 0.897 \\
\hline Infant pain-related distress & -0.02 & -0.00 & -0.18 & 0.854 \\
\hline Caregiver worry pre-needle (preschool) & -0.02 & -0.00 & -0.34 & 0.735 \\
\hline Caregiver sensitivity (preschool) & 0.05 & 0.04 & 0.62 & 0.536 \\
\hline Caregiver CP behaviors pre-needle (preschool) & 0.05 & 0.05 & 0.69 & 0.494 \\
\hline Caregiver DP behaviors pre-needle (preschool) & -0.02 & -0.05 & -0.29 & 0.772 \\
\hline Preschooler coping outcome pre-needle & -0.12 & -0.00 & -1.51 & 0.131 \\
\hline Preschooler executive functioning & 0.09 & 0.00 & 0.94 & 0.348 \\
\hline Preschooler language & 0.23 & 0.01 & 2.43 & 0.015 \\
\hline \multicolumn{5}{|l|}{ Caregiver sensitivity (preschool) } \\
\hline Caregiver sensitivity (preschool) caregiver sensitivity (infancy) & 0.24 & 0.01 & 3.53 & $<0.001$ \\
\hline \multicolumn{5}{|l|}{ Preschooler language } \\
\hline Caregiver sensitivity (infancy) & 0.18 & 0.22 & 2.26 & 0.024 \\
\hline Caregiver verbal reassurance (infancy) & 0.19 & 5.72 & 2.33 & 0.020 \\
\hline \multicolumn{5}{|l|}{ Preschooler executive functioning } \\
\hline Caregiver proximal soothing & -0.24 & -1.94 & -3.06 & 0.002 \\
\hline \multicolumn{5}{|l|}{ Caregiver worry pre-needle (preschool) } \\
\hline Infant pain-related distress & 0.15 & 0.09 & 2.40 & 0.016 \\
\hline
\end{tabular}

$\mathrm{CP}$, coping-promoting; DP, distress-promoting. 


\section{Table 5}

\section{Standardized and unstandardized estimates for model 2: predicting preschool coping responses at 2 minutes post-vaccination} from infant and preschool predictors.

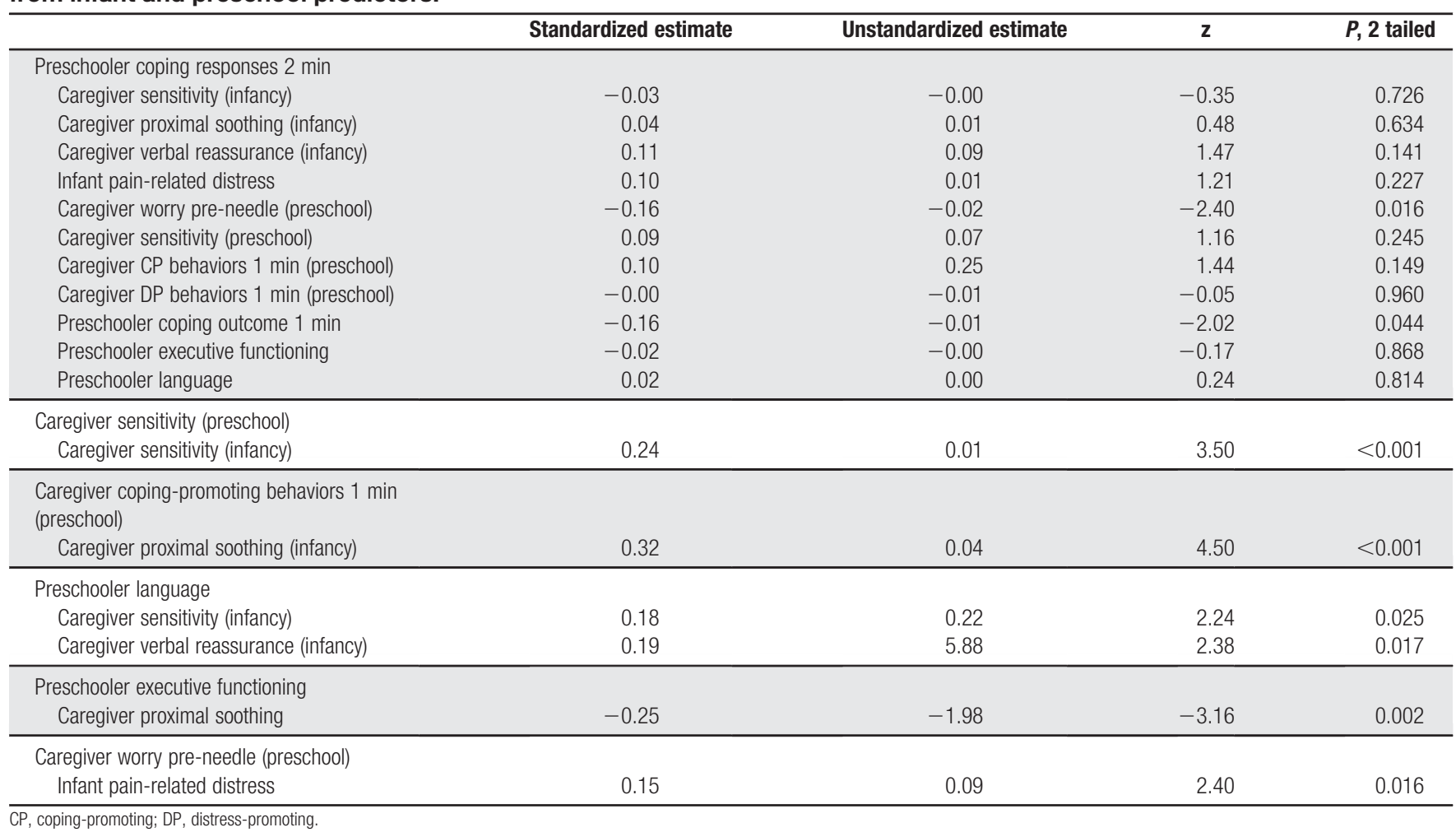

Unexpectedly, model 1 displayed that caregiver proximal soothing at the 12-month vaccination directly predicted preschooler coping responses at 1 minute $(B=0.17, P=0.036)$ (ie, the relationship did not involve caregiver behavior at the preschool vaccination).

\subsubsection{Caregiver behavior during 12-month vaccination to preschooler cognitive ability to preschooler vaccination behavior pathways}

Caregiver sensitivity from the 12-month vaccination positively predicted preschooler's language abilities across all 4 models

\section{Table 6}

Standardized and unstandardized estimates for model 3: predicting preschool coping outcomes at 1 minute post-vaccination from infant and preschool predictors.

\begin{tabular}{|c|c|c|c|c|}
\hline & Standardized estimate & Unstandardized estimate & $\mathbf{z}$ & $P, 2$ tailed \\
\hline \multicolumn{5}{|l|}{ Preschooler coping outcome $1 \mathrm{~min}$} \\
\hline Caregiver sensitivity (infancy) & 0.07 & 0.06 & 1.22 & 0.222 \\
\hline Caregiver proximal soothing (infancy) & 0.05 & 0.39 & 0.78 & 0.435 \\
\hline Caregiver verbal reassurance (infancy) & 0.06 & 1.39 & 1.06 & 0.292 \\
\hline Infant pain-related distress & -0.06 & -0.14 & -1.00 & 0.319 \\
\hline Caregiver worry pre-needle (preschool) & 0.04 & 0.13 & 0.69 & 0.492 \\
\hline Caregiver sensitivity (preschool) & -0.05 & -1.16 & -0.77 & 0.439 \\
\hline Caregiver CP behaviors pre-needle (preschool) & 0.01 & 0.35 & 0.16 & 0.877 \\
\hline Caregiver DP behaviors pre-needle (preschool) & 0.07 & 5.13 & 1.05 & 0.294 \\
\hline Preschooler coping outcome pre-needle & 0.48 & 0.49 & 8.00 & $<0.001$ \\
\hline Preschooler executive functioning & 0.04 & 0.05 & 0.61 & 0.541 \\
\hline Preschooler language & -0.11 & -0.08 & -1.52 & 0.129 \\
\hline \multicolumn{5}{|l|}{ Caregiver sensitivity (preschool) } \\
\hline Caregiver sensitivity (infancy) & 0.24 & 0.01 & 3.48 & $<0.001$ \\
\hline \multicolumn{5}{|l|}{ Preschooler language } \\
\hline Caregiver sensitivity (infancy) & 0.17 & 0.21 & 2.15 & 0.032 \\
\hline Caregiver verbal reassurance (infancy) & 0.18 & 5.65 & 2.29 & 0.022 \\
\hline \multicolumn{5}{|l|}{ Preschooler executive functioning } \\
\hline Caregiver proximal soothing & -0.24 & -1.92 & -3.03 & 0.002 \\
\hline \multicolumn{5}{|l|}{ Caregiver worry pre-needle (preschool) } \\
\hline Infant pain-related distress & 0.16 & 0.10 & 2.44 & 0.015 \\
\hline
\end{tabular}

$\mathrm{CP}$, coping-promoting; DP, distress-promoting. 
Table 7

Standardized and unstandardized estimates for model 4: predicting preschool coping outcomes at 2 minutes post-vaccination from infant and preschool predictors.

\begin{tabular}{|c|c|c|c|c|}
\hline & Standardized estimate & Unstandardized estimate & $\mathbf{z}$ & $P, 2$ tailed \\
\hline \multicolumn{5}{|l|}{ Preschooler coping outcome 2 min } \\
\hline Caregiver sensitivity (infancy) & -0.00 & -0.00 & -0.07 & 0.945 \\
\hline Caregiver proximal soothing (infancy) & 0.05 & 0.29 & 0.83 & 0.406 \\
\hline Caregiver verbal reassurance (infancy) & -0.05 & -0.91 & -1.05 & 0.293 \\
\hline Infant pain-related distress & -0.03 & -0.06 & -0.63 & 0.527 \\
\hline Caregiver worry pre-needle (preschool) & 0.04 & 0.10 & 0.80 & 0.426 \\
\hline Caregiver sensitivity (preschool) & -0.02 & -0.31 & -0.32 & 0.748 \\
\hline Caregiver CP behaviors 1 min (preschool) & 0.18 & 9.61 & 3.15 & 0.002 \\
\hline Caregiver DP behaviors 1 min (preschool) & -0.03 & -1.34 & -0.47 & 0.638 \\
\hline Preschooler coping outcome $1 \mathrm{~min}$ & 0.67 & 0.50 & 12.80 & $<0.001$ \\
\hline Preschooler executive functioning & -0.08 & -0.06 & -1.28 & 0.202 \\
\hline Preschooler language & 0.06 & 0.03 & 0.92 & 0.359 \\
\hline \multicolumn{5}{|l|}{ Caregiver sensitivity (preschool) } \\
\hline Caregiver sensitivity (infancy) & 0.24 & 0.01 & 3.53 & $<0.001$ \\
\hline \multicolumn{5}{|l|}{$\begin{array}{l}\text { Caregiver coping-promoting behaviors } 1 \mathrm{~min} \\
\text { (preschool) }\end{array}$} \\
\hline Caregiver proximal soothing (infancy) & 0.31 & 0.04 & 4.41 & $<0.001$ \\
\hline \multicolumn{5}{|l|}{ Preschooler language } \\
\hline Caregiver sensitivity (infancy) & 0.18 & 0.22 & 2.24 & 0.025 \\
\hline Caregiver verbal reassurance (infancy) & 0.19 & 5.86 & 2.38 & 0.017 \\
\hline \multicolumn{5}{|l|}{ Preschooler executive functioning } \\
\hline Caregiver proximal soothing & -0.25 & -1.98 & -3.15 & 0.002 \\
\hline \multicolumn{5}{|l|}{ Caregiver worry pre-needle (preschool) } \\
\hline Infant pain-related distress & 0.16 & 0.10 & 2.44 & 0.015 \\
\hline
\end{tabular}

$(B=0.18, P=0.024 ; B=0.18, P=0.025 ; B=0.17, P=0.032 ;$ $B=0.18, P=0.025$, respectively). Caregiver verbal reassurance from the 12-month vaccination positively predicted preschooler's language abilities across all 4 models $(B=0.19, P=0.020 ; B=0.19$, $P=0.017 ; B=0.18, P=0.022 ; B=0.19, P=0.017)$. Preschooler language ability in turn predicted preschooler coping responses at 1 minute post-needle (model $1 ; B=0.23, P=0.015$ ).

Caregiver proximal soothing at the 12 -month vaccination predicted more optimal preschooler executive functioning $(B=-0.24, P$ $=0.002$ ). Executive functioning challenges in turn did not significantly predict any of the dependent variables across the 4 models.

\subsubsection{Twelve-month vaccination behavior to caregiver cognition at preschool vaccination to caregiver behavior at preschool vaccination to preschooler vaccination behavior pathway}

Infant pain-related distress at the 12-month vaccination positively predicted caregiver worry pre-needle at the preschool vaccination ( $B=0.15, P=0.016$ ) across the 4 models, whereby higher pain at the 12-month vaccination predicted higher caregiver worry at the preschool vaccination. In turn, caregiver worry pre-needle at the preschool vaccination did not significantly predict any caregiver behaviors at the preschool vaccination across the 4 models. However, model 2 unexpectedly demonstrated that caregiver preneedle worry directly predicted preschooler coping responses at 2 minutes post-needle ( $B=-0.15, P=0.016$ ) (ie, this relationship did not involve caregiver behavior at the preschool vaccination).

\subsubsection{Twelve-month vaccination behavior to preschooler vaccination behavior pathway}

Infant pain-related distress at the 12-month vaccination did not directly predict preschooler coping responses or outcomes in any model. However, model 2 displayed that the preschooler coping outcome (ie, pain-related distress) at 1 minute did predict less coping responses at 2 minutes post-needle $(B=-0.16, P=$ 0.044). Moreover, both model 3 and model 4 demonstrated that the preschooler coping outcome from the preceding epoch predicted the preschooler coping outcome at the following epoch ( $B=0.48, P<0.001 ; B=0.67, P<0.001$, respectively).

\subsection{Post hoc analyses}

Our path analyses unexpectedly indicated that, with the exception of caregiver coping-promoting behaviors at 1 minute post-needle at the preschool vaccination positively predicting the preschooler coping outcome at 2 minutes post-needle, caregiver coping-promoting and distress-promoting behaviors did not significantly predict subsequent preschooler coping responses or outcomes.

Accordingly, a series of post hoc correlations were run to determine whether concurrent relationships between these variables existed (ie, when these caregiver and preschooler variables were measured at the same point in time). Specifically, 2 sets of correlations were run between caregiver coping-promoting behaviors, distress-promoting behaviors, preschooler coping responses, and preschooler coping outcomes. The first set of correlations pertained to the bivariate relationships between caregiver coping- and distresspromoting behaviors (at the preschool vaccination) and preschooler coping responses 1 minute pre-needle, 1 minute post-needle, and 2 minutes post-needle. The second set of correlations pertained to the bivariate relationships between caregiver coping- and distress-promoting behaviors and preschooler coping outcomes 1 minute pre-needle, 1 minute post-needle, and 2 minutes post-needle. 


\subsubsection{Set 1 of post hoc correlations: concurrent relationships between caregiver coping-promoting behaviors, distress- promoting behaviors, and preschooler coping responses}

Prior to the first needle, caregiver coping-promoting behaviors were positively related to preschooler coping responses $(r=$ $0.44, P<0.001)$ and caregiver distress-promoting behaviors were negatively related to preschooler coping responses $(r=$ $-0.16, P=0.021)$. At 1 minute following the last needle, caregiver coping-promoting behaviors were positively related to preschooler coping responses $(r=0.20, P=0.004)$ and caregiver distress-promoting behaviors were negatively related to preschooler coping responses $(r=-0.28, P<0.001$, respectively). At 2 minutes following the last needle, caregiver coping-promoting behaviors were positively related to preschooler coping responses $(r=0.49, P<0.001)$ and caregiver distress-promoting behaviors were negatively related to preschooler coping responses $(r=-0.24, P<0.001)$.

\subsubsection{Set 2 of post hoc correlations: concurrent relationships between caregiver coping-promoting behaviors, distress- promoting behaviors, and preschooler coping outcomes}

Prior to the first needle, caregiver coping-promoting behaviors were negatively related to the preschooler coping outcome $(r=$ $-0.15, P=0.037)$, and caregiver distress-promoting behaviors were positively related to the preschooler coping outcome $(r=$ $0.42,<0.001)$. At 1 and 2 minutes following the last needle, caregiver distress-promoting behaviors were positively related to preschooler coping outcomes $(r=0.45, P<0.001 ; r=0.38, P<$ 0.001 , respectively). Caregiver coping-promoting behaviors were not related to preschooler coping outcomes at 1 and 2 minutes following the last needle $(r=0.05, P=0.505 ; r=-0.10, P=$ 0.177 , respectively).

\section{Discussion}

This was the first study to conduct an autoregressive crosslagged path model to examine 3 types of relationships between children's coping responses and coping outcomes simultaneously (study 1). Moreover, this study was the first to use a longitudinal design that incorporated the potential influences of caregiver cognitive-affective and behavioral variables, as well as children's cognitive abilities (study 2). Collectively, these 2 studies present a highly in-depth analysis of preschooler coping with vaccination pain and provide novel insights into this dynamic and multifaceted construct.

Important to note is that while "coping outcomes" must be construed from a multidimensional perspective, ${ }^{34}$ the present article was solely focused on the behavioral dimension of painrelated distress.

\subsection{Study 1: the relationships between children's coping responses and outcomes in the preschool vaccination context}

Ultimately, study 1 demonstrated that coping responses and outcomes during needle-related procedures are separate, but interrelated, aspects of the coping process and that the relationships between them are dynamic, changing over time. Unexpectedly, children's pain-related distress did not predict subsequent coping responses, nor did children's coping responses predict subsequent pain-related distress. A similar pattern was found for caregiver coping- and distress-promoting behaviors in study 2. In line with previous research, ${ }^{1,17,25}$ children's pain strongly predicts subsequent children's pain prospectively. An integration of these findings with a focus on clinical implications will be presented in our conclusion.

\subsection{Study 2: preschool children's coping responses and outcomes in the vaccination context: caregiver and child predictors from infancy and preschool}

A host of novel relationships (both longitudinal and concurrent) were elucidated.

First, higher levels of caregiver sensitivity and proximal soothing during the 12-month vaccination predicted parallel caregiver behaviors (caregiver sensitivity and coping-promoting behaviors, respectively) at the preschool vaccination. However, caregiver sensitivity at the preschool vaccination did not significantly predict preschooler coping responses or outcomes. Previous work from our cohort suggested consistency in caregiver sensitivity during vaccinations across the first year of life. ${ }^{36}$ These results now extend this finding across the first 5 years of childhood. In regard to caregiver sensitivity at preschool not predicting children's coping responses and outcomes, this finding differs from the infant literature linking caregiver sensitivity to infant distress regulation. ${ }^{15,21,28,36}$ This may reflect that the overall quality of caregiving is not as important during the preschool vaccination because of the child's developing self-regulatory abilities.

Second, proximal soothing during the 12-month vaccination positively predicted caregiver coping-promoting behaviors at 1 minute during the preschool vaccination. This suggests a consistency between caregiver behaviors viewed as helpful in infancy and parallel caregiver behaviors viewed as helpful in childhood. Counter to predictions, caregiver coping-promoting and distresspromoting behaviors did not, as a whole, predict children's subsequent coping responses or outcomes. A possible explanation is provided when discussing the post hoc correlations.

While it may seem counterintuitive at first, caregiver copingpromoting behaviors at 1 minute positively predicted the coping outcome at 2 minutes (ie, higher distress). However, examining the model as a whole, caregiver coping-promoting behavior at 1 minute seems to be involved in 2 different concurrent pathways leading to children's coping outcomes at 2 minutes (1 direct and 1 indirect). Specifically, caregiver coping-promoting behavior at 1 minute directly predicts suboptimal coping outcomes at 2 minutes and indirectly predicts more optimal coping outcomes at 2 minutes through being related to lower caregiver distresspromoting behaviors at 1 minute (which is related to lower painrelated distress at 1 minute which then predicts forward to lower pain-related distress at 2 minutes). Taken together, this finding speaks to the complex interplay between caregiver and child interactions in the context of coping. Taking any 1 type of caregiver behavior out of the context of the other behaviors he or she is concurrently engaging in leads to an incomplete picture. Coping-promoting behavior that is related to less distresspromoting behavior is what is critical to a reduction in subsequent pain expression in the preschooler.

Third, higher caregiver sensitivity and verbal reassurance at the 12-month vaccination both predicted better developed children's language abilities at preschool, while higher proximal soothing at the 12-month vaccination predicted more optimal executive functioning. Only preschooler language ability in turn predicted greater preschool coping responses at 1 minute. Our finding that better developed children's language predicted more optimal children's coping responses provides novel evidence for the importance of language abilities in preschoolers' pain-related coping responses and early parental sensitivity for supporting this 
language development. Our finding that children's executive functioning was not predictive of coping was surprising. We speculate that preschooler coping in the needle-related context is not yet subsumed by the higher level cognitive processes involved in executive functioning.

Fourth, higher pain-related distress from the 12-month vaccination predicted higher caregiver worry at the preschool vaccination, but caregiver worry did not then predict any caregiver behaviors at the preschool vaccination. Unexpectedly, worry directly negatively predicted preschooler coping responses at 2 minutes. This suggests that more caregiver worry pre-needle predicts fewer child coping responses at 2 minutes, but that this is not related to caregiver verbal behaviors. Perhaps, it is caregivers' nonverbal behaviors at the preschool vaccination, such as proximal soothing, which provide the link between caregiver worry and preschooler coping responses.

Finally, pain-related distress from infancy did not predict preschooler coping responses or coping outcomes. In addition, both studies in this article showed that preschooler coping outcomes predict subsequent coping outcomes. This finding replicates findings from the 12 -month vaccination. ${ }^{36}$ Taken together, these findings suggest that over the first 5 years of early childhood, children's pain predicts children's pain prospectively in the short term (ie, within a vaccination appointment) but not longitudinally.

Our finding that caregiver coping- and distress-promoting behaviors at preschool did not predict subsequent preschoolers' coping responses or outcomes was surprising, given the previous research studies. ${ }^{10,11,18,23,43}$ However, when we conducted post hoc correlations to examine concurrent relationships, important clarifications were found.

Concurrent relationships were observed between caregiver behaviors (both coping- and distress-promoting) and children's coping responses and outcomes. Specifically, caregiver copingpromoting behaviors related to optimal preschooler coping responses at all 3 epochs. This suggests the importance of encouraging ongoing coping responses in children for immediate benefits. In addition, caregiver coping-promoting behaviors were only related to optimal coping outcomes during the pre-needle phase. On the other hand, caregiver distress-promoting behaviors related to less optimal preschooler coping responses and outcomes at all 3 epochs. Taking it 1 step further, there was also a difference in the strength of the relationships, depending on whether it was a coping- or distress-promoting behavior (distress-promoting behaviors had much stronger relationships with coping outcomes). Taken together, these findings suggest that having caregivers not engage in distress-promoting behaviors may be much more important than having caregivers engage in coping-promoting behaviors.

\subsection{Conclusion}

This article has elucidated transactional and longitudinal pathways predicting preschooler coping responses and outcomes in the vaccination setting. Synthesizing across all models in both studies, 3 broad conclusions are offered.

First, preschooler's coping responses and coping outcomes during vaccination are separate, but interrelated, aspects of the coping process. The relationships between them are dynamic and change over time. Our findings provide empirical support for the value of investigating these 2 different aspects of children's coping across different phases of needle-related procedures (ie, reactivity and regulation), which place different physical and psychological demands on the child.
Second, caregivers play an important role in preschool children's coping and this role is both longitudinal and concurrent. From a longitudinal perspective, caregiver sensitivity and proximal soothing during stressful infant events have important developmental influences not only on young children's coping responses at the preschool vaccination but also on broader cognitive development as well. In addition, the caregiver behaviors that related most strongly to preschooler coping responses and outcomes were those taking place concurrently. Furthermore, caregiver behavioral analysis should be multifaceted, with caregiver behavior being analyzed in the context of the other caregiver behaviors that are concurrently being enacted.

Third, the strongest relationships observed prospectively in the current paper were those pertaining to the same characteristic. Specifically, children's pain predicted children's pain across the preschooler vaccination appointment at the highest magnitude observed across all relationships.

Based on these conclusions, several clinical implications are offered. First, a preschooler's ability to cope is a powerful tool to reduce pain-related distress. However, coping responses must be encouraged to be ongoing throughout the vaccination until the distress has been regulated because results indicate that good coping during 1 time point does not predict lower pain-related distress at a subsequent time point. Second, proximal soothing and caregiver sensitivity during infancy are critical to encourage because of both short- and long-term implications to not just children's pain-related coping but also to broader cognitive abilities such as language and executive functioning. Third, it is as important or perhaps even more important for caregivers of preschoolers undergoing vaccination to be taught to avoid distress-promoting behaviors (such as criticism, reassurance), in addition to enacting coping-promoting behaviors. Fourth, synthesizing over both studies, it is crucial that caregiver copingpromoting behaviors and child coping responses be enacted continuously and that caregiver distress-promoting behaviors be avoided continuously. Results suggest that these caregiver and child behaviors do not "pay forward" to reduce pain-related distress or increase coping responses at subsequent time points. Finally, given our finding that children's pain predicts children's pain prospectively within a vaccination appointment, but not longitudinally, preschoolers during vaccination should have their distress reduced well before the needle pierces his or her skin, and caregivers should not assume that their child's level of pain during the 12-month vaccination will be indicative of their level of pain at preschool.

\subsection{Limitations and future directions}

Generalizability will be affected by the education level of the sample and the self-selection bias associated with being a caregiver who agrees to be followed through the first year of vaccinations, again at the preschool vaccination, and participate in a comprehensive preschool assessment. It is also important to acknowledge the observational design of our study and, more specifically, that the relationships between the variables in our models are not necessarily causal. It is possible that the relationships between the variables in our model could be explained by unmeasured variables (eg, temperament explaining the link between coping outcomes over time). In addition, the small-to-moderate size of several path coefficients must be kept in mind. All clinical implications offered above should be considered in the context of these points.

Future research should build on our findings by conducting similar multivariate longitudinal models. Re-examining the role of 
children's language and executive functioning at later developmental stages may shed further light on the influence of these developing subsystems. In line with the idea of coping outcomes as multidimensional ${ }^{34}$ and to continue moving in the field of pediatric pain and coping forward, future research is needed that examines additional dimensions of coping outcomes (eg, the viewpoints of others, physiological measures, child procedural compliance, etc.) Moreover, future research should explore whether certain coping outcomes may be more or less adaptive than others. Other interesting avenues for future research would be to examine whether nonverbal caregiver behaviors (eg, physical touch, nonverbal distraction) relate to young children's coping with pain and to investigate whether young children's coping with pain relates to other areas of well-being (eg, socioemotional functioning). Finally, research in older children should examine more covert and cognitively advanced approaches to coping with pain (eg, self-talk, distracting oneself, or cognitive reframing).

\section{Conflict of interest statement}

The authors have no conflicts of interest to declare.

This research was funded by research grants to R. Pillai Riddell from the Canadian Institutes of Health Research and the Canadian Foundation for Innovation, and salary support from her inaugural York Research Chair in Pain and Mental Health. L. Campbell received awards from the Canadian Institutes of Health Research and is a recipient of the Meighen Wright Graduate Scholarship in Maternal-Child Health, the LaMarsh Centre for Child and Youth Research Student Award, and the Ontario Mental Health Foundation (OMHF) Research Studentship. L. Campbell is a trainee member of Pain in Child Health, a Strategic Training Initiative in Health Research of the Canadian Institutes of Health Research.

\section{Acknowledgments}

The authors thank the staff at both S. Greenberg's and H. Garfield's clinics, the graduate student clinical leads involved in the psychological assessments, and all OUCH lab research assistants for their assistance and ongoing support. Also, they thank all the families who have participated in this research.

\section{Supplemental video content}

Supplemental video content associated with this article can be found online at http://links.lww.com/PAIN/A497.

\section{Article history:}

Received 6 July 2017

Received in revised form 11 September 2017

Accepted 21 September 2017

Available online 26 October 2017

\section{References}

[1] Ahola Kohut S, Pillai Riddell R. Does the neonatal facial coding system differentiate between infants experiencing pain-related and non-painrelated distress? J Pain 2009;10:214-20.

[2] Arbuckle JL. Full information estimation in the presence of incomplete data. Adv Struct equation Model Issues Tech 1996;243:277.

[3] Arbuckle JL. Amos 19.0. O. Chicago: Smallwaters, 2010.

[4] Atkinson NH, Gennis H, Racine NM, Pillai Riddell R. Caregiver emotional availability, caregiver soothing behaviors, infant pain during immunization. J Pediatr Psychol 2015:40:1105-14.
[5] Bentler RM. EQS 6 structural equations program manual. Encino: Multivariate Software, 2004.

[6] Bernier A, Carlson SM, Whipple N. From external regulation to selfregulation: early parenting precursors of young children's executive functioning. Child Dev 2010;81:326-39.

[7] Biringen Z. The emotional availability (EA) scales. 4th ed. Fort Collins. Available at: http://www.emotionalavailability.com/.

[8] Biringen Z, Derscheid D, Vliegen N, Closson L, Easterbrooks MA. Emotional availability (EA): theoretical background, empirical research using the EA scales, and clinical applications. Dev Rev 2014;34: 114-67.

[9] Blackwell PL. The influence of touch on child development: implications for intervention. Infants Young Child 2000;13:25-39.

[10] Blount RL, Bunke V, Cohen LL, Forbes CJ. The Child-Adult Medical Procedure Interaction Scale-Short Form (CAMPIS-SF): validation of a rating scale for children's and adults' behaviors during painful medical procedures. J Pain Symptom Manage 2001;22:591-9.

[11] Blount RL, Cohen LL, Frank NC, Bachanas PJ, Smith AJ, Manimala MR, Pate JT. The child-adult medical procedure interaction scale-revised: an assessment of validity. J Pediatr Psychol 1997; 22:73-88.

[12] Blount RL, Landolf-Fritsche B, Powers SW, Sturges JW. Differences between high and low coping children and between parent and staff behaviors during painful medical procedures. J Pediatr Psychol 1991;16: 795-809.

[13] Bollen KA. Structural equations with latent variables. New York: Wiley, 1989.

[14] Bradley RH, Caldwell BM, Rock SL, Ramey CT, Barnard KE, Gray C, Hammond MA, Mitchell S, Gottfried AW, Siegel L, Johnson DL. Home environment and cognitive development in the first 3 years of life: a collaborative study involving six sites and three ethnic groups in North America. Dev Psychol 1989;25:217.

[15] Braungart-Rieker J, Garwood MM, Powers BP, Notaro PC. Infant affect and affect regulation during the still-face paradigm with mothers and fathers: the role of infant characteristics and parental sensitivity. Dev Psychol 1998;34:1428.

[16] Campbell L, DiLorenzo M, Atkinson N, Riddell RP. Systematic review: a systematic review of the interrelationships among children's coping responses, children's coping outcomes, and parent cognitive-affective, behavioral, and contextual variables in the needle-related procedures context. J Pediatr Psychol 2017;42:611-621.

[17] Campbell L, Riddell RP, Garfield H, Greenberg S. A cross-sectional examination of the relationships between caregiver proximal soothing and infant pain over the first year of life. PAIN 2013;154:813-23.

[18] Cohen LL, Bernard RS, Greco LA, McClellan CB. A child-focused intervention for coping with procedural pain: are parent and nurse coaches necessary? J Pediatr Psychol 2002;27:749-57.

[19] Cohen LL, Bernard RS, McClelland CB, MacLaren JE. Assessing medical room behavior during infants' painful procedures: the measure of adult and infant soothing and distress (MAISD). Children Health Care 2005;34: 81-94.

[20] Corbett BA, Constantine LJ, Hendren R, Rocke D, Ozonoff S. Examining executive functioning in children with autism spectrum disorder, attention deficit hyperactivity disorder and typical development. Psychiatry Res 2009; 166:210-22

[21] Din Osmun L, Pillai Riddell R, Flora DB. Infant pain-related negative affect at 12 months of age: early infant and caregiver predictors. J Pediatr Psychol 2014;39:23-34.

[22] Din Osmun L, Pillai Riddell R, Gordner S. Brief report: maternal emotional availability and infant pain-related distress. J Pediatr Psychol 2009;34: $722-6$.

[23] Frank NC, Blount RL, Smith AJ, Manimala MR, Martin JK. Parent and staff behavior, previous child medical experience, and maternal anxiety as they relate to child procedural distress and coping. J Pediatr Psychol 1995;20: 277-89.

[24] Gioia GA, Espy KA, Isquith PK. Behavior rating inventory of executive function-preschool version. Lutz, FL: Psychological Assessment Resources, 2003.

[25] Hillgrove-Stuart J, Pillai Riddell R, Horton R, Greenberg S. Toy-mediated distraction: clarifying the role of distraction agent and preneedle distress in toddlers. Pain Res Manag 2013;18:197-202.

[26] Hu LT, Bentler PM. Cutoff criteria for fit indexes in covariance structure analysis: conventional criteria versus new alternatives. Struct Equ Modeling 1999;6:1-55.

[27] Kessler RC, Greenberg DF. Linear panel analysis. New York: Academic Press, 1981.

[28] Leerkes EM. Predictors of maternal sensitivity to infant distress. Parenting Sci Pract 2010;10:219-39. 
[29] Lewis M, Goldberg S. Perceptual-cognitive development in infancy: a generalized expectancy model as a function of the mother-infant interaction. Merrill Palmer Q Behav Dev 1969;15:81-100.

[30] Lisi D, Campbell L, Pillai Riddell R, Garfield H, Greenberg S. Naturalistic parental pain management during immunizations during the first year of life: observational norms from the OUCH cohort. PAIN 2013;154:1245-53.

[31] Loehlin JC. Latent variable models: an introduction to factor, path, and structural analysis. New York, NY: Lawrence Erlbaum Associates Publishers, 1998.

[32] Merkel S, Voepel-Lewis T, Shayevitz JR, Malviya S. The FLACC: a behavioral scale for scoring postoperative pain in young children. Pediatr Nurs 1997;23:293-7.

[33] NICHD Early Child Care Research Network. Chronicity of maternal depressive symptoms, maternal sensitivity, and child functioning at 36 months. Dev Psychol 1999;35:1297-310.

[34] NICHD Early Child Care Research Network. Child care and motherchild interaction in the first three years of life. Dev Psychol 1999;35: 1399-413.

[35] Pederson DR, Moran G. Expressions of the attachment relationship outside of the strange situation. Child Dev 1996;67:915-27.

[36] Pillai Riddell R, Campbell L, Flora DB, Racine N, Osmun LD, Garfield H, Greenberg S. The relationship between caregiver sensitivity and infant pain behaviors across the first year of life. PAIN 2011;152:2819-26.

[37] Pillai Riddell RR, Racine N, Craig K, Campbell L. Psychological theories and models in pediatric pain. In: McGrath P, Stevens B, Walker S, Zempsky W, editors. The oxford textbook of pediatric pain. Oxford: Oxford University Press, 2013. p. 85-94.

[38] Racine NM, Riddell RR, Flora D, Garfield H, Greenberg S. A longitudinal examination of verbal reassurance during infant immunization: occurrence and examination of emotional availability as a potential moderator. J Pediatr Psychol 2012;37:935-44.
[39] Racine NM, Riddell RR, Flora DB, Taddio A, Garfield H, Greenberg S. Predicting preschool pain-related anticipatory distress: the relative contribution of longitudinal and concurrent factors. PAIN 2016;157: 1918-32.

[40] Rudolph KD, Dennig MD, Weisz JR. Determinants and consequences of children's coping in the medical setting: conceptualization, review, and critique. Psychol Bull 1995;118:328.

[41] Siegel LJ, Smith KE. Coping and adaptation in children's pain. In: Children in pain. Springer US, 1991. p. 149-70.

[42] Skinner EA, Zimmer-Gembeck MJ. The development of coping. Annu Rev Psychol 2007;58:119-44.

[43] Spagrud LJ, von Baeyer CL, Ali K, Mpofu C, Fennell LP, Friesen K, Mitchell J. Pain, distress, and adult-child interaction during venipuncture in pediatric oncology: an examination of three types of venous access. J Pain Symptom Manage 2008;36:173-84.

[44] Steiger JH. EzPATH: causal modeling: a supplementary module for SYSTAT and SYGRAPH: PC-MS-DOS, Version 1.0. Systat. 1989.

[45] Taddio A, Nulman I, Koren BS, Stevens B, Koren G. A revised measure of acute pain in infants. J Pain Symptom Manage 1995;10:456-63.

[46] Tarabulsy GM, Provost MA, Bordeleau S, Trudel-Fitzgerald C, Moran G, Pederson DR, Trabelsi M, Lemelin JP, Pierce T. Validation of a short version of the maternal behavior $\mathrm{Q}$-set applied to a brief video record of mother-infant interaction. Infant Behav Dev 2009;32:132-6.

[47] Taylor C, Sellick K, Greenwood K. The influence of adult behaviors on child coping during venipuncture: a sequential analysis. Res Nurs Health 2011;34:116-31.

[48] Waxman JA, DiLorenzo MG, Riddell RR, Flora DB, Greenberg S, Garfield H. Preschool needle pain responding: establishing "normal." J Pain 2017; 18:739-745.

[49] Wechsler D. Wechsler preschool and primary scale of intelligence-third edition: Canadian. Toronto: NCS Pearson Inc, 2004. 